Louisiana State University

LSU Digital Commons

Faculty Publications

Department of Geography \& Anthropology

$12-1-2019$

\title{
Morphologic adjustments of actively evolving highly curved neck cutoffs
}

Derek Richards

Louisiana State Univ, Dept Geog \& Anthropol, drich79@lsu.edu

Kory Konsoer

Louisiana State Univ, Coastal Studies Inst

Follow this and additional works at: https://digitalcommons.Isu.edu/geoanth_pubs

Part of the Geography Commons

\section{Recommended Citation}

Richards, Derek and Konsoer, Kory, "Morphologic adjustments of actively evolving highly curved neck cutoffs" (2019). Faculty Publications. 103.

https://digitalcommons.Isu.edu/geoanth_pubs/103

This Article is brought to you for free and open access by the Department of Geography \& Anthropology at LSU Digital Commons. It has been accepted for inclusion in Faculty Publications by an authorized administrator of LSU Digital Commons. For more information, please contact gcoste1@lsu.edu. 


\title{
Special Issue Paper
}

\section{Morphologic adjustments of actively evolving highly curved neck cutoffs}

\author{
Derek Richards $^{1 *}$ (D) and Kory Konsoer ${ }^{1,2}$ iD \\ ${ }^{1}$ Department of Geography and Anthropology, Louisiana State University, 227 Howe-Russell-Kniffin Geoscience Complex, Baton \\ Rouge, LA 70803, USA \\ ${ }^{2}$ Coastal Studies Institute, Louisiana State University, 331 Howe-Russell-Kniffin Geoscience Complex, Baton Rouge, LA 70803, USA
}

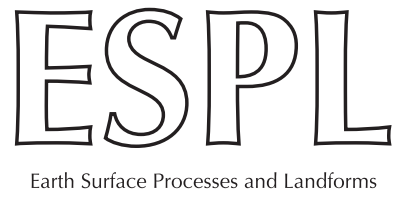

\begin{abstract}
Neck cutoffs and their resultant oxbow lakes are important and prominent features of riverine landscapes. Detailed field-based research focusing on the morphologic evolution of neck cutoffs is currently insufficient to fully characterize cutoff evolution. High-resolution bathymetric data were collected over 3 years for the purpose of determining channel morphology and morphologic change on three actively evolving neck cutoffs. Results indicate the following general trends in morphologic adjustment: (1) a longitudinal bar in the upstream meander limb that develops near the entrance to the abandoned bend; (2) a deep scour hole in the downstream meander limb immediately downstream of the cutoff channel; (3) erosion of the bank opposite the cutoff in the downstream meander limb; (4) a cutoff bar in the downstream meander limb at the junction corner of the cutoff channel and the downstream meander limb; and (5) perching of the exit of the abandoned bend above the cutoff channel due to channel bed incision. The results presented herein were used to develop a conceptual model that depicts the morphologic evolution of highly curving neck cutoffs. The findings of this research are combined with recent analyses of the three-dimensional flow structure through neck cutoffs to provide a mechanistic explanation for the morphodynamics of neck cutoffs. (c) 2019 John Wiley \& Sons, Ltd.
\end{abstract}

KEYWORDS: neck cutoffs; meandering rivers; channel morphology; difference mapping

\section{Introduction}

As a meandering river migrates through its floodplain, the length and sinuosity of the channel can increase while the channel slope decreases (Phillips, 2010). Under these circumstances it may no longer be optimal for the river to transport water and sediment downstream, which can lead to cutoff of the meander bend, resulting in a decrease in channel length and an increase in local gradient and sediment transport capacity (Fisk, 1947; Phillips, 2010). Following cutoff, the entrance and exit of the abandoned meander bend become plugged with relatively coarse sediment, transitioning into an oxbow lake, and eventually becoming terrestrialized floodplain following fine-grained sedimentation (Fisk, 1947; Allen, 1965; Johnson and Paynter, 1967; Gagliano and Howard, 1984). Generally, cutoffs are categorized as chute or neck cutoffs (Fisk, 1947; Allen, 1965). Chute cutoffs form during overbank flow events that have the ability to scour a channel across the floodplain (Fisk, 1947; Allen, 1965). Neck cutoffs form when the upstream and downstream meander limbs migrate towards one another and the narrow land of floodplain that separates the channels is breached (Fisk, 1947; Allen, 1965; Gagliano and Howard, 1984). Meander cutoffs are classified as neck cutoffs when the distance across the floodplain between the upstream and downstream channels is less than one bankfull channel width apart at the time of breach (Lewis and Lewin, 1983).

A considerable amount of work has been done on meandering river cutoffs, ranging from the long-term behaviour and organization of meandering rivers (Stolum, 1996, 1998; Hooke, 2004; Camporeale et al., 2005, 2008; Constantine and Dunne, 2008; Micheli and Larsen, 2011), mechanisms of cutoff initiation (Ratzlaff, 1981; Gay et al., 1998; Constantine et al., 2010b; Grenfell et al., 2012, 2014), rates of infill and sedimentology of oxbow lakes and floodplain alluvial architecture (Petersen, 1963; Erskine et al., 1982; Bridge et al., 1986; Piégay et al., 2002; Brooks and Medioli, 2003; Wren et al., 2008; Citterio and Piégay, 2009; Toonen et al., 2012; Dieras et al., 2013; Ishii and Hori, 2016), cutoff types and distribution within meandering rivers (Lewis and Lewin, 1983), hydrodynamics of cutoffs and the abandoned channel (Constantine et al., 2010a; Le Coz et al., 2010; Zinger et al., 2013; Costigan and Gerken, 2016; Richards et al., 2018), and morphologic changes following cutoff (Johnson and Paynter, 1967; Mosley, 1975; Gagliano and Howard, 1984; Hooke, 1995; Fares, 2000; Fuller et al., 2003; Han and Endreny, 2014). Based on the work mentioned 
above, several factors can be identified that provide first-order constraints on the morphologic evolution of meander cutoffs, namely (1) length of channel removed via cutoff, (2) planform geometry prior to cutoff, and (3) sediment composition of the channel bed.

A feature shown to be of importance in the morphologic evolution of cutoff channels is the diversion angle between the cutoff channel and the abandoned channel (Fisk, 1947; Gagliano and Howard, 1984; Shields and Abt, 1989; Constantine et al., 2010a). Previous research has suggested that larger diversion angles correspond to faster rates of sediment plugging of the abandoned bend and that neck cutoffs generally have larger diversion angles than chute cutoffs (Fisk, 1947; Gagliano and Howard, 1984). The mechanism behind plugging is a zone of flow separation and recirculation that forms as flow enters the abandoned bend, resulting in the reduction of flow velocity and shear stress (Constantine et al., 2010a). The width of the flow separation zone scales with the diversion angle, where larger diversion angles produce wider zones of flow separation and recirculation (Constantine et al., 2010a). Thus, larger diversion angles lead to faster rates of deposition and plugging due to wider zones of flow separation (Constantine et al., 2010a).

Related to the diversion angle of cutoffs is the hydrodynamic phenomenon known as the Bulle effect. The effect was quantified on diversions where one channel laterally branches off at a given angle from the main channel, which continues on a straight path. Research on these diversions has shown that a disproportionate amount of bedload sediment enters the diversion channel compared to the water discharge ratio between the two channels (Bulle, 1926; Dutta et al., 2017). The amount of bedload entering the diversion channel increases as the diversion angle increases from $\sim 10$ to $120^{\circ}$ (Bulle, 1926; Dutta et al., 2017). This phenomenon is associated with near-bed flow being diverted into the diversion channel, which is responsible for transporting bedload into the channel, and near-surface flow primarily continuing into the main channel (Bulle, 1926; Dutta et al., 2017; Dutta and Garcia, 2018). A zone of flow separation forms within the diversion channel and as the diversion angle increases, the width of the flow separation zone increases (Bulle, 1926; Dutta et al., 2017; Dutta and Garcia, 2018), similarly related to the findings for cutoff channels (Shields and Abt, 1989; Constantine et al., 2010a).

A conceptual model for the hydrodynamics and the resulting change in channel morphology during the evolution of chute cutoffs has been established which suggests that processes occurring at chute cutoffs are similar to those observed for bifurcations and confluences (Zinger et al., 2013). The bifurcation-confluence model for chute cutoffs represents one stage in chute cutoff evolution, illustrating the time immediately after the cutoff channel has been established and before the abandoned bend has been fully plugged with sediment (Zinger et al., 2013). A similar model has not yet been established for neck cutoffs. Instead, the current pre-existing conceptual model for neck cutoffs is a generalized model for the long-term morphologic evolution, showing four main stages from active meandering river to active neck cutoff, lacustrine (oxbow lake), and terrestrialized floodplain (Gagliano and Howard, 1984) (Figure 1).

The long-term neck cutoff model addresses evolutionary factors at each stage that drive neck cutoffs to move to the next stage in evolution (Gagliano and Howard, 1984), but does not address in detail the complex hydrodynamics that happen during the 'neck cutoff stage' (i.e. stage 2 of Figure 1) or the morphologic change that results. However, with recent advancements in hydroacoustic technologies, such as multibeam echo sounding (MBES) and acoustic Doppler current profiling (ADCP), detailed measurements of

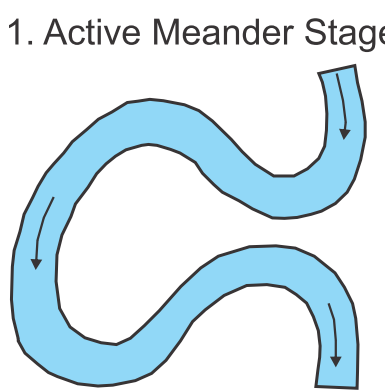

2. Neck Cutoff Stage

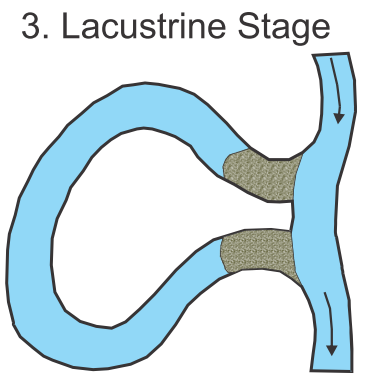

4. Terrestrialized Stage

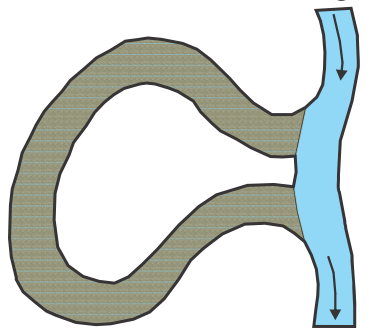

Figure 1. Conceptual model showing the long-term evolution of neck cutoffs on meandering rivers. Note that, as depicted, the cutoff location results in a relatively straight channel segment connecting upstream and downstream limbs (modified from Gagliano and Howard, 1984). [Colour figure can be viewed at wileyonlinelibrary.com]

the hydrodynamic and morphologic adjustments during the active cutoff stage are now increasingly possible. Furthermore, the long-term conceptual model depicts the 'neck cutoff stage' as a simplified geometry where the location of the cutoff relative to the meander bend results in a straight channel segment that connects the upstream and downstream limbs, which we herein refer to as omega-style $(\Omega$-style). However, in many natural meandering rivers, the location of a neck cutoff can result in a range of cutoff channel geometries ranging from mildly to highly curving (Figure 2).

Recently, a conceptual model was introduced for the hydrodynamics occurring within highly curved neck cutoffs (Figure 3) that illustrates the following key points: (1) primary flow being redirected $\sim 180^{\circ}$ through the cutoff area, with high momentum fluid advected to the opposite bank downstream of the cutoff; (2) areas of flow recirculation at the entrance and exit of the abandoned bend and on the adjacent bank in the downstream meander limb; and (3) patterns of secondary circulation within the cutoff region indicating near-surface fluid oriented towards the abandoned bend and near-bed fluid oriented into the downstream meander limb (Richards et al., 2018). These findings highlight the complexity of the three-dimensional flow field that can occur when neck cutoff channels are not straight, yet do not present the corresponding morphologic adjustments that occur for highly curved neck cutoffs.

Previous research describing neck cutoff morphology has shown different morphologic responses depending on site specifics, such as planform geometry. An experimental study of a neck cutoff developed in a stream table showed that as a cutoff forms, the bed elevation upstream of the point of cutoff is lowered through erosion and elevations downstream are raised by deposition (Han and Endreny, 2014). Field investigations suggest that the upstream meander limb tends to straighten, resulting in flow travelling through the cutoff channel in a relatively straight path from the upstream to the downstream limb of the bend, increasing velocity and depth at the point of cutoff (Fisk, 1947; Gagliano and Howard, 1984; Hooke, 1995). As the cutoff channel widens, localized bed scour in the downstream meander limb close to the 

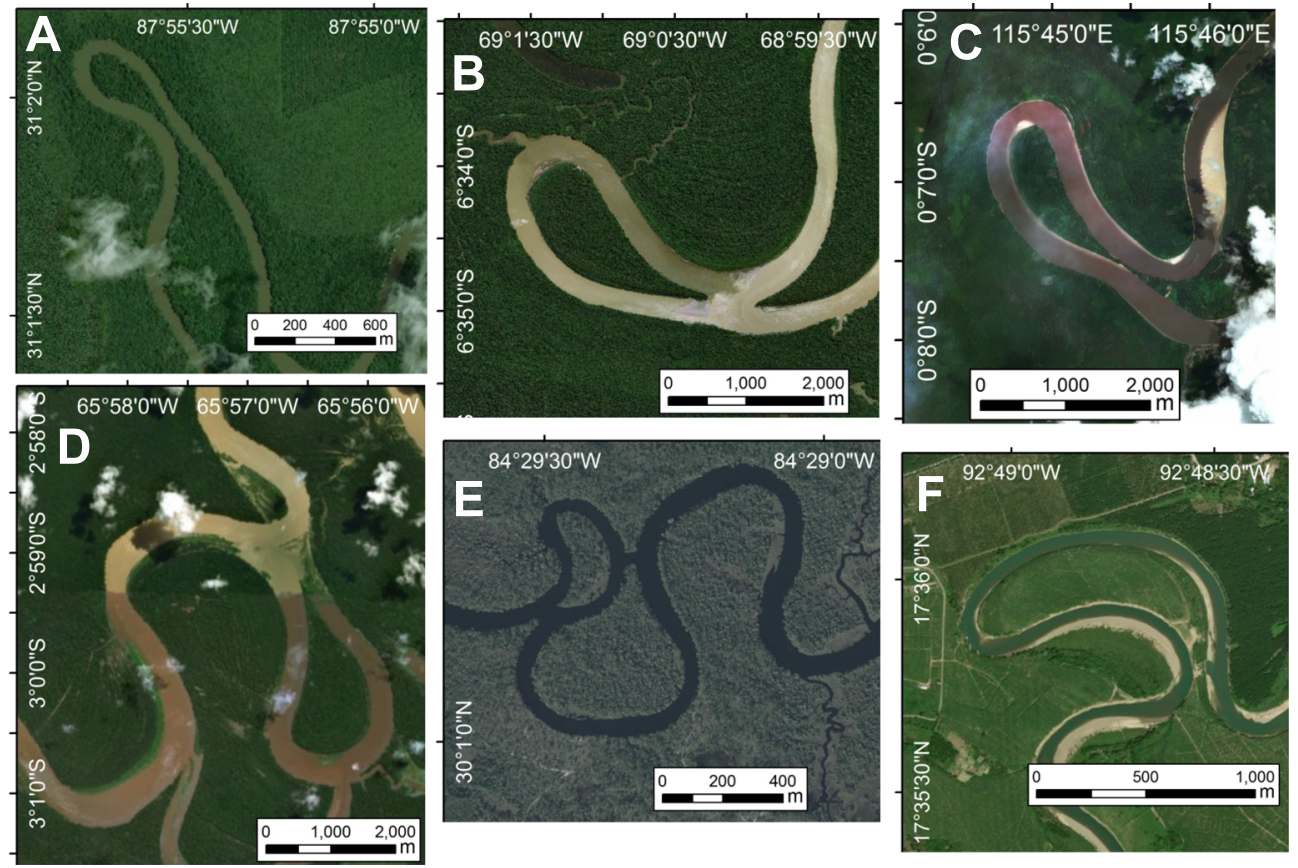

Figure 2. Examples of meandering rivers exhibiting planform geometries that result in highly curving neck cutoffs: (A) Tensaw River, Alabama, USA; (B) Juruá River, State of Amazonas, Brazil; (C) Mahakam River, West Kutai Regency, Indonesia; (D) Juruá River, State of Amazonas, Brazil, near confluence with the Amazon River; (E) Ochlockonee River, Florida, USA; (F) Grijalva River, State of Tabasco, Mexico. [Colour figure can be viewed at wileyonlinelibrary.com]

bank opposite the cutoff channel occurs, along with sediment deposition within the entrance and exit of the abandoned bend (Hooke, 1995; Han and Endreny, 2014). Additionally, both field (Hooke, 1995) and experimental work (Han and Endreny, 2014) have documented the formation of a bar at the downstream junction corner of the cutoff channel and the downstream meander limb.

Few detailed field studies have been performed on the morphologic changes of relatively large (channel widths greater than $\sim 150 \mathrm{~m}$ ) actively evolving neck cutoffs with highly curved planform configurations. There is also a lack of studies that document and link the detailed morphologic changes within neck cutoffs to the three-dimensional hydrodynamics. This paucity of information is problematic given that neck cutoffs with highly curved planform configurations can be observed all over the world from the study sites used in this research on the White River, Arkansas to the Juruá River in Brazil, the Mahakam River in Indonesia, and the Grijalva River in Mexico, to name just a few (Figure 2).

This research aims to address the lack of knowledge described above by documenting in detail the morphologic evolution of three actively evolving neck cutoffs with highly curving planform configurations prior to full abandonment of the original bend over a period of 3 years from 2015 to 2017. The results are discussed within the context of a recent study examining the three-dimensional hydrodynamics of these same cutoff sites (Richards et al., 2018) to provide a more comprehensive insight into the morphodynamics of highly curved neck cutoffs. The findings from this study are summarized into a conceptual model of neck cutoff morphology for highly curving cutoff channels at a stage in the evolutionary process between breach of floodplain and prior to complete plugging of the abandoned bend. The generalizability of the conceptual model is demonstrated by comparing planform evolution of various highly curving neck cutoffs observed in different environmental settings around the world.

\section{Study Area}

Three neck cutoffs were researched along an $\sim 18 \mathrm{~km}$ span of the lower White River, located between De Valls Bluff and Clarendon, Arkansas (Figure 4). The lower White River starts near Batesville, Arkansas and flows for $\sim 745 \mathrm{~km}$ before it feeds into the Mississippi River, $\sim 17 \mathrm{~km}$ northeast of Watson, Arkansas. The drainage area is $\sim 8360 \mathrm{~km}^{2}$, the bankfull width is $\sim 170 \mathrm{~m}$, and the bankfull depth is $\sim 7 \mathrm{~m}$. The closest river gauge is a United States Geological Survey (USGS) station at De Valls Bluff, Arkansas (gauge: 07077000). The gauging station indicates a mean annual discharge of $770 \mathrm{~m}^{3} \mathrm{~s}^{-1}$ and a peak annual discharge of $\sim 2480 \mathrm{~m}^{3} \mathrm{~s}^{-1}$. Seasonality of the flow generally displays higher discharges occurring between March-June and lower discharges between JulyDecember. The sinuosity for this portion of the river is $\sim 2.2$ and migration rates are $\sim 2-4$ myear $^{-1}$; upstream of Clarendon, Arkansas the channel slope is about $6 \times 10^{-4}(\mathrm{Ed}$ wards et al., 2015).

The three cutoffs of this study formed on elongate meander loops with highly curved planform configurations (Richards et al., 2018) and are at different stages in their morphologic evolution yet fall in the stage after initial breach of the floodplain but before complete disconnection and plugging of the abandoned bend. The elongate planform morphology of these bends, as well as the location of the cutoff within the bend, establishes hydrodynamic conditions such that the upstream and downstream limbs are roughly parallel, with flow moving in opposite directions (Richards et al., 2018). Pumps Bend (PB), the furthest upstream and most recent cutoff event of the three sites, began cutoff in 2013. Seven Mile Bend (SB), located $\sim 9 \mathrm{~km}$ downstream from PB and roughly halfway between Pumps and Franklin bends, cutoff in 2011. Franklin Bend (FB) cutoff in 2005, making it the farthest downstream and the oldest of the cutoff sites. The width of the floodplain necks before cutoff, determined by satellite imagery, was about 30, 20, and $15 \mathrm{~m}$ for $\mathrm{PB}, \mathrm{SB}$, and FB, respectively (Figure 4). 


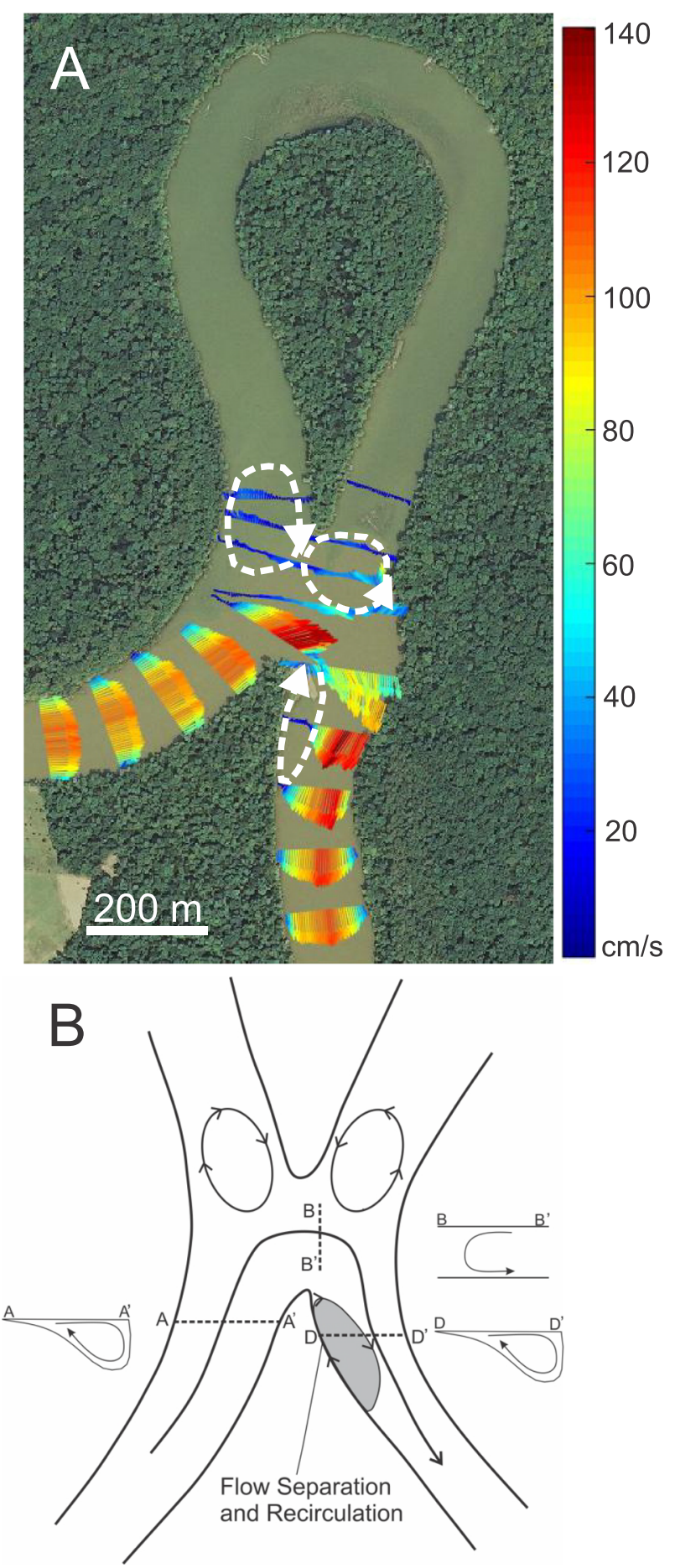

Figure 3. (A) Depth-averaged velocity vectors on Franklin Bend of the White River in central Arkansas from a field campaign on 07/04/2015. (B) Conceptual model of flow structure through highly curving neck cutoffs showing zones flow separation of recirculation (modified from Richards et al., 2018). [Colour figure can be viewed at wileyonlinelibrary.com]

The lower White River provides an excellent opportunity to conduct detailed, process-based field investigations of the neck cutoff process due to the relative abundance of neck cutoffs that evolve slowly enough to obtain high-resolution data on an annual basis. PB, SB, and FB bends are all still connected to the active channel of the White River and do not appear to be adjusting very fast towards disconnection and oxbow lake formation. For comparison, previous rates for full disconnection of abandoned bends have ranged from less than 1 year to within 10 years (Petersen, 1963; Gagliano and Howard, 1984; Hooke, 1995). The lower White River flows through mostly forested floodplains, including the sites focused on for this research. The planform geometry of the White River is that of a sinuous meandering channel with multiple neck cutoffs and numerous other bends with narrow necks suggesting imminent cutoff. Interestingly, there is an apparent lack of chute cutoffs on the river despite regular overbank flooding, an explanation for which requires additional studies. The lower White River also includes the Dale Bumpers White River National Wildlife Refuge, located along the lower $\sim 100 \mathrm{~km}$ of the river, which is one of the largest remaining bottomland hardwood forests in the Mississippi River valley.

\section{Methods}

Data were collected over a period of 3 years from 2015 to 2017. In 2015, channel morphology was surveyed using a Teledyne-RDI Workhorse Rio Grande acoustic Doppler current profiler with an integrated Hemisphere A100 differential global positioning system (dGPS). While ADCP is typically used to collect three-dimensional velocity measurements, it also records depths and can be used to generate bed morphology maps. ADCP was used to collect data along predetermined cross-sections oriented perpendicular to the channel and along longitudinal lines at each site between 6 and 7 April 2015 when discharge was $\sim 1600$ and $\sim 1580 \mathrm{~m}^{3} \mathrm{~s}^{-1}$, respectively, corresponding to a near-bankfull event. ADCP measurements were processed in WinRiver II and exported to the Velocity Mapping Toolbox (VMT), which is a suite of codes in MATLAB used to process and visualize boat-mounted ADCP data (Parsons et al., 2013). Channel depths were exported from VMT and brought into iRIC, a river flow and riverbed analysis software package that allows for interpolation of values by creating a grid that defines the path and extent of the river channel (i-ric. org). In iRIC, a 10-m resolution bathymetric surface was interpolated, as well as an interpolated water elevation surface using an estimated water slope from USGS gauging stations at De Valls Bluff and Clarendon, Arkansas. These two surfaces were brought into ArcMap, where the channel depths were subtracted from the water elevation surface to obtain channel bed elevations. A final 5-m resolution bathymetry map was created using Caris Base Editor.

Surveys of channel bed morphology in 2016 and 2017 were conducted using a NORBIT iWMBSc (compact integrated wideband multibeam sonar) with an integrated inertial motion unit (IMU) and dGPS. Surveys in 2016 were conducted from 17 to 18 May, when the average daily discharge was 1020 and $\sim 1015 \mathrm{~m}^{3} \mathrm{~s}^{-1}$, respectively. The river stage was $\sim 1 \mathrm{~m}$ below bankfull stage. Surveys in 2017 were conducted from 22 to 27 May during a large overbank flood event, with discharges of about $2770-2370 \mathrm{~m}^{3} \mathrm{~s}^{-1}$. Post-processing, filtering, and visualization of the multibeam data were conducted using Caris HIPS/SIPS, a software package designed to handle large bathymetric datasets. A post-processing kinematic (PPK) solution was used to convert channel depths to bed elevations. Data collected at FB on 22 May 2017 were obtained on a day when the nearest CORS base station was not working properly; therefore, PPK motion and elevation offsets applied to the data did not result in reliable elevations. Thus, a manual shift was applied to the FB 22/05/2017 survey so that bed elevations near the apex of the abandoned bend were in agreement with the FB 2016 survey (under the assumption of negligible vertical accretion in this region between the two surveys).

Difference maps were created in Caris HIPS/SIPS by subtracting the elevation maps between consecutive years. Maps of channel morphology derived from the multibeam data were initially gridded at $0.5 \mathrm{~m}$ resolution, however, the 


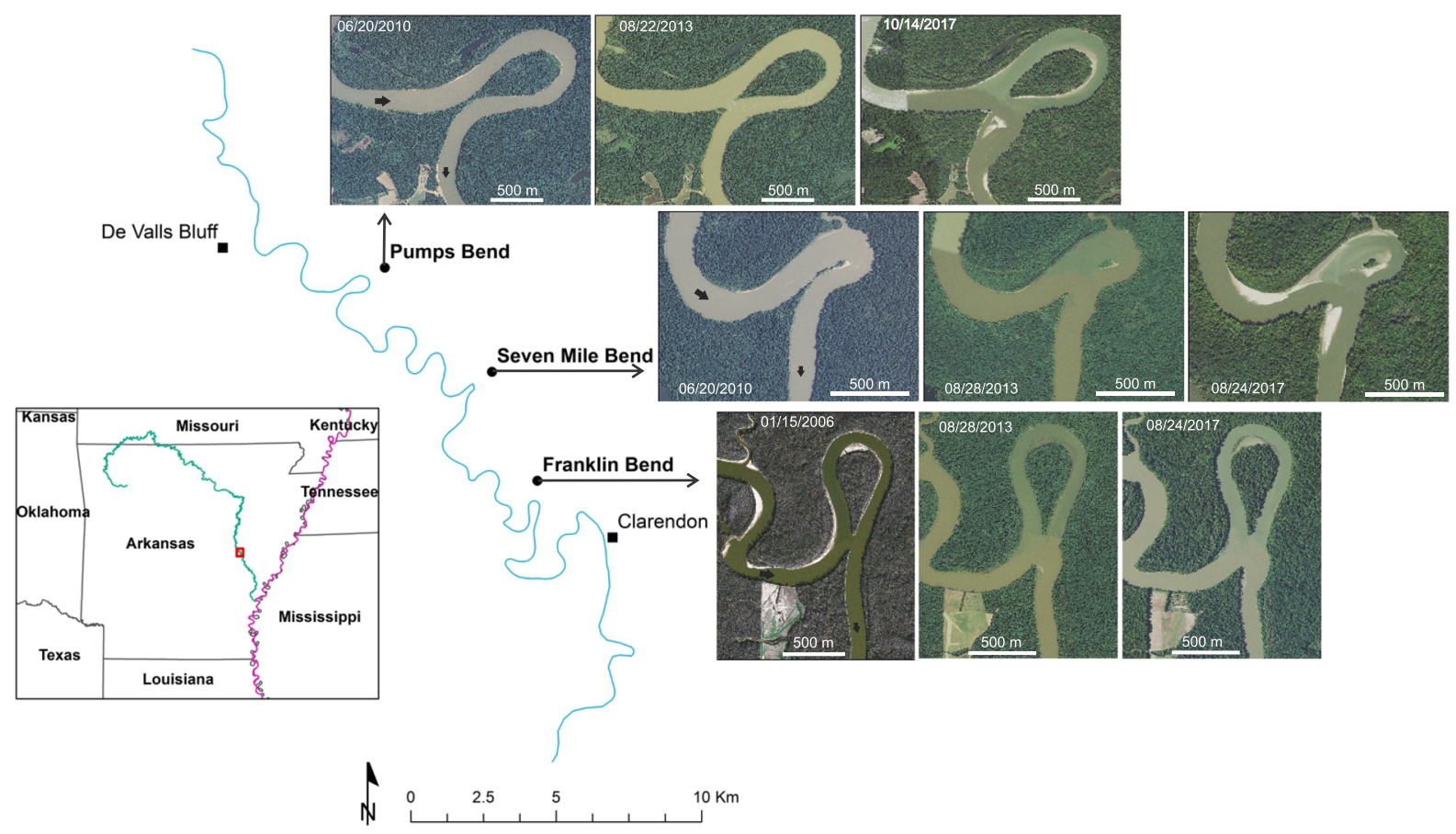

Figure 4. Study area along the White River in Central Arkansas showing the location of Pumps Bend, Seven Mile Bend, and Franklin Bend neck cutoffs. The three cutoffs are located between De Valls Bluff and Clarendon, Arkansas. Pumps Bend cutoff in 2014, Seven Mile Bend in 2011, and Franklin Bend in 2006. [Colour figure can be viewed at wileyonlinelibrary.com]

difference maps produced from these surfaces emphasized differences in bedform morphology that were not the focus of this study. Rather, the purpose of this study was to focus on general changes in bed morphology, thus the resolution was increased to $1.5 \mathrm{~m}$, which still provided highly detailed channel bed morphology maps. The difference maps were then exported, with values $\pm 0.2 \mathrm{~m}$ excluded for maps using the 2015 ADCP data, and values $\pm 0.05 \mathrm{~m}$ excluded for maps using strictly multibeam data. Elevation profile lines were created in Caris HIPS/SIPS, and background aerial imagery was downloaded from USGS Earth Explorer website.

To systematically compare the morphologic features and rates of change observed at each of the three neck cutoff sites, dimensionless analyses are presented. Maximum lateral erosion distances $D_{e}$ were determined by measuring orthogonal bankline distances between different time intervals following initial formation of each neck cutoff, and annual rates of migration $M_{r}$ were calculated as $D_{\Theta} / t$, where $t$ is the time interval between measurements. Aerial imagery from Google Earth was used to supplement the field surveys of this study, with FB including years 2006, 2009, 2010, and 2012 and SB including imagery from 2012. For PB, all 3 years of field surveys were used in the dimensionless analysis, whereas for FB and SB, only 2015-2017 field surveys were used because the rates of change were considerably less. Measurements of each neck cutoff width $W_{c}$ were also made for each time interval, with cutoff width measured as the shortest distance between the upstream junction corner and the island between the entrance and exit to the abandoned bend. These distances were made dimensionless by using the reach-averaged bankfull width.

The bathymetric data utilized in this study were all acquired during near-bankfull to over-bankfull discharge events to optimize survey coverage and time efficiency during the multibeam surveys. Thus, the measurements do not offer insight into the range of morphologic adjustments that would occur during relatively lower discharge events in any given year. One of the primary objectives of this study was to document and quantify morphologic change during actively evolving neck cutoffs. During the early stages of neck cutoff evolution, morphologic rates of change are typically fastest, and therefore it is justifiable to use the measurements presented in this study to address the overall geomorphic evolution of early neck cutoff change. During later stages of neck cutoff evolution, rates of change are typically slower (Hooke, 1995), and it is likely that annual hydrologic and morphologic variability could have an impact on the annual difference maps presented herein. However, if we assume that bankfull discharge represents a formative discharge event, and thus reflects an equilibrium between process and form, then annual bathymetric comparisons during formative discharge events are also justifiable for the purposes of this study.

\section{Results}

Throughout the results section two terms are used that we define here. The point of cutoff is the area where the floodplain neck was first breached and the river incised. This term is used instead of the more conventional 'cutoff channel' because the distance of floodplain cutoff is extremely short compared to bankfull width, and thus not necessarily comprising a new channel. We define a cutoff bar as the bar complex that forms adjacent to the cutoff in the downstream meander limb.

\subsection{Characteristics of Pumps Bend cutoff morphology}

The 2015 survey at PB was performed less than 2 years after initial breaching of the floodplain that resulted in $\sim 2300 \mathrm{~m}$ of stream length removal (Figure 5A). The upstream limb of PB exhibits a slight curvature, and the channel bed morphology upstream of the point of cutoff shows an asymmetric transverse profile with higher elevations along the left bank (opposite cutoff) (Figure 5A). At the point of cutoff, an $\sim 10 \mathrm{~m}$ deep and $\sim 67 \mathrm{~m}$ wide $(\sim 61 \%$ of bankfull width) notch is incised into the floodplain neck. Adjacent to this notch is a $\sim 105 \mathrm{~m}$ wide portion of the floodplain that has been lowered $\sim 1-2 \mathrm{~m}$ below 

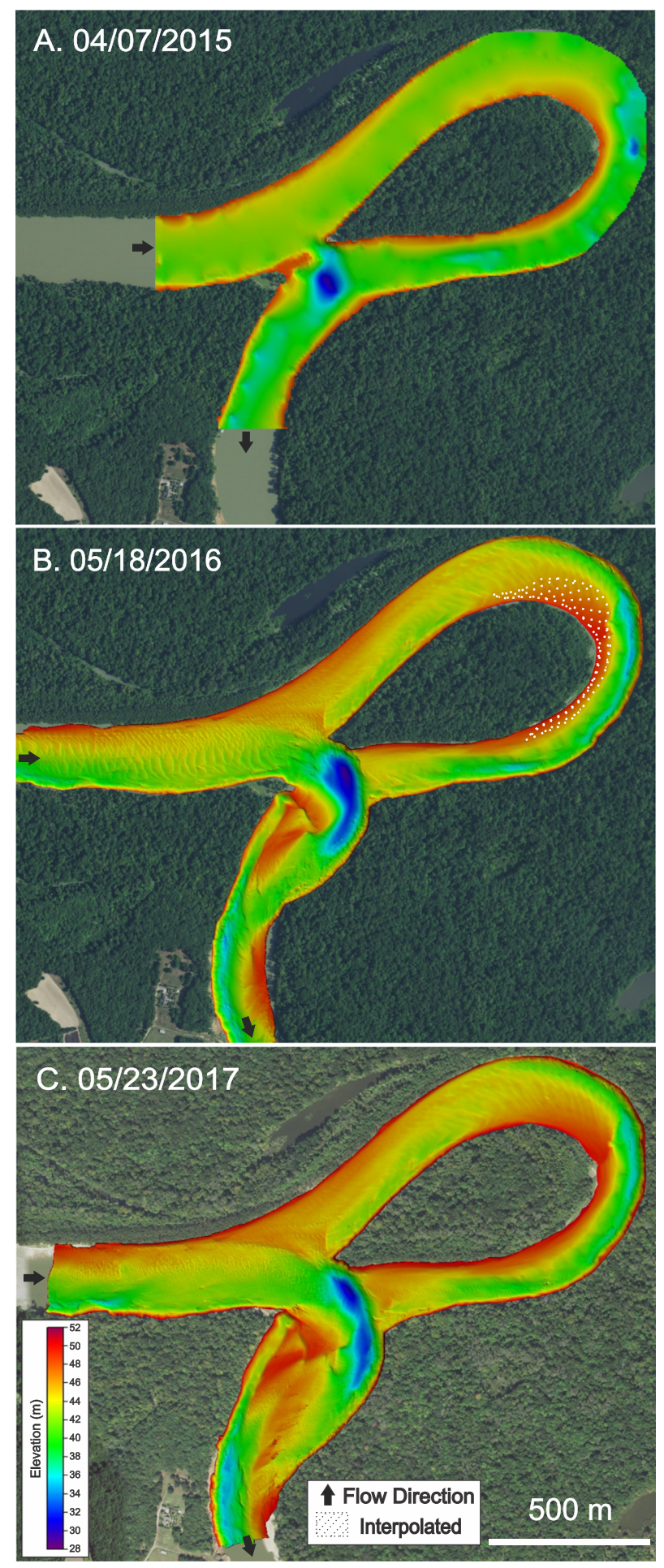

Figure 5. (A) Pumps Bend 2015 channel morphology generated at a $5 \mathrm{~m}$ resolution. (B) Pumps Bend 2016 channel morphology generated at a $1.5 \mathrm{~m}$ resolution. (C) Pumps Bend 2017 channel morphology generated at a $1.5 \mathrm{~m}$ resolution. For all three images, warmer colours represent higher elevations and cooler colours represent lower elevations. Channel morphology located under white dashed polygons indicates areas of relatively large surface interpolation. [Colour figure can be viewed at wileyonlinelibrary.com]

bankfull stage, but has yet to be fully incised into the surrounding channel bed elevations (Figure 5A). Since the initial cutoff, a deep scour hole developed directly downstream of the point of cutoff and grew to $\sim 90 \mathrm{~m}$ wide. The scour hole is roughly circular in shape with a minimum elevation of $\sim 29 \mathrm{~m}$, or $\sim 20 \mathrm{~m}$ deeper than the average floodplain elevation. At the abandoned bend apex, the channel morphology shows a point bar along the inner bank and a weakly defined thalweg that transitions to the right bank within the downstream limb of the bend. The entrance and exit of the abandoned bend do not show evidence of plug formation at the time of this survey, indicating that the bend is still hydrologically connected to the active river.

The PB point of cutoff in 2016 widened to $~ 196 \mathrm{~m}$ ( 115\% of bankfull width), resulting in a straightening of the upstream limb into the cutoff (Figure 5B). In the upstream limb, the multibeam survey shows dunes spanning most of the channel width except for the lower elevations along the right bank. The dunes appear to wash out at the point of cutoff where bed morphology transitions into a scour hole. The scour hole morphology has changed considerably since the 2015 survey, now exhibiting an elongate form and extending outward towards the bank opposite the cutoff. The scour hole is $\sim 330 \mathrm{~m}$ long and the upstream portion has a maximum width of $\sim 95 \mathrm{~m}$, while the downstream portion has a width of $\sim 50 \mathrm{~m}$. The lowest elevation is $\sim 29 \mathrm{~m}$, which is $\sim 16 \mathrm{~m}$ deeper than the exit of the abandoned bend (Figure 5B). The 2016 survey also shows substantial bank erosion of up to $\sim 80 \mathrm{~m}(\sim 47 \%$ of bankfull width) along the bank opposite the cutoff point, which extends within the downstream limb of the active channel for $\sim 420 \mathrm{~m}$, as indicated by the concave appearance of the bank. Evidence of erosion of the bank is not apparent in the 2015 morphology. The erosion on this bank gradually diminishes in the downstream direction until the width of the channel becomes similar to that of the reach-averaged bankfull width.

A striking feature in the 2016 multibeam survey is the cutoff bar that formed adjacent to the point of cutoff and downstream of the scour hole. This cutoff bar is $\sim 440 \mathrm{~m}$ in length, with a maximum width $\sim 155 \mathrm{~m}$ immediately downstream of the cutoff and decreasing in width downstream. The cutoff bar displays a non-uniform morphology, composed of more than one bar front, with one bar front oriented transverse to the bank of the downstream meander limb and others oriented nearly parallel to the downstream bankline. The highest elevations of this cutoff bar are $\sim 50 \mathrm{~m}$, which is $\sim 1-2 \mathrm{~m}$ below average local floodplain elevation. The cutoff bar does not appear to be fully attached to the bank, as a smaller channel ( $35 \mathrm{~m}$ in width) can be seen between the cutoff bar and the bank, likely representing the previous thalweg of the channel. Dunes are present on the downstream tail of the cutoff bar, with an orientation towards the right bank rather than the downstream direction. Downstream of the cutoff bar, channel curvature and bed morphology reverse where a thalweg is located along the right bank and a point bar is present on the left bank.

At the entrance to the abandoned bend, channel bed elevations increase slightly, and bedform geometries quickly reduce in size. Interestingly, the bedforms entering the abandoned bend terminate abruptly along a linear front oriented roughly $\mathrm{N}-\mathrm{S}$ (Figure $5 \mathrm{~B}$ ). The bed morphology within the abandoned bend is much more apparent in the 2016 multibeam survey compared to the 2015 ADCP survey. Within the abandoned bend, a thalweg can be seen along the right bank, which transitions to the left bank upstream of the bend apex. Immediately downstream of the bend apex, the thalweg is more pronounced and is present to the exit of the abandoned bend. Large dunes are present in the abandoned bend as the channel transitions into the bend apex, but appear to wash out immediately downstream of the apex. At the exit of the abandoned bend, bedforms are observed with dune asymmetry indicating upstream migration into the abandoned bend. Additionally, the channel morphology at the exit of the abandoned bend displays a marked contrast in bed elevation with the adjacent scour hole, as evidenced by the sharp delineation along the northern portion of this area (Figure 5B). 
The PB 2017 multibeam survey shows a continued straightening of the upstream limb at the cutoff junction corner (Figure 5C). Dunes are still present in the upstream meander limb, but are substantially smaller in wavelength and amplitude. The width of the cutoff point has expanded to $\sim 240 \mathrm{~m}$ ( $140 \%$ of bankfull width). The scour hole is still elongated in shape but has appeared to narrow, being $\sim 65 \mathrm{~m}$ wide in the upstream portion and $\sim 60 \mathrm{~m}$ wide in the downstream portion. The erosion of the concave bank opposite the cutoff in the downstream meander limb has experience an additional $\sim 80 \mathrm{~m}$ lateral migration, and extends for $\sim 635 \mathrm{~m}$ downstream until widths become similar to reach-averaged bankfull width. The cutoff bar is $\sim 330 \mathrm{~m}$ in length, $\sim 190 \mathrm{~m}$ wide at the upstream end of the bar, and is still separated from the bank by a small channel. There is now an area of higher elevation in the middle of the channel, with elevations $\sim 5 \mathrm{~m}$ higher than the surrounding river bed.

Morphologic changes within the abandoned bend appear to be minimal when compared to the 2016 survey. However, at the exit to the abandoned bend, dunes can be seen that extend for $\sim 500 \mathrm{~m}$ upstream into the bend. A longitudinal profile along this region reveals that the dunes are migrating upstream into the abandoned bend (Figure 6). This profile also shows the increase in bed elevation from $\sim 39$ to $\sim 46 \mathrm{~m}$ as the downstream limb of the abandoned bend approaches the exit (Figure 6).

\subsection{Characteristics of Franklin Bend and Seven Mile Bend cutoff morphology}

The neck cutoffs occurring at FB and SB exhibit many morphologic similarities to those observed at PB, such as a distinct cutoff bar, marked erosion of the bank opposite the cutoff, dunes in the upstream limb that wash out into the cutoff, and a pronounced scour hole within the downstream limb of the bend (Figures 7 and 8). Rather than reiterate the details of these similarities for all three sites, the focus of this next section is on the morphologic features observed for FB and SB cutoffs that are not present in the bathymetric maps for PB.

One of the more noticeable morphologic features present at FB cutoff, observed in both the 2016 and 2017 multibeam datasets, is the curvilinear ridges that extend from the left bank in the upstream limb towards the cutoff (Figures 7B and C). Three curvilinear ridges are present, separated by intervening swales, with the ridge closest to the entrance to the abandoned bend having the highest elevations and extending $\sim 90 \mathrm{~m}$ from the bank. In contrast, the multibeam bathymetric maps for SB cutoff reveal only a single curvilinear ridge that extends from the left bank across the entrance of the abandoned bend towards the cutoff (Figures $8 \mathrm{~B}$ and $\mathrm{C}$ ).

At $\mathrm{FB}$, between the scour hole and the exit of the abandoned bend is an area of unit bars with bedforms migrating upstream towards the entrance of the abandoned bend, with an average bed elevation of $\sim 42 \mathrm{~m}$ (or $\sim 4-5 \mathrm{~m}$ lower than the exit of the abandoned bend). A similar composite bar is observed at SB between the entrance and exit of the abandoned bend, however this bar at SB lacks discernible bedforms (Figures 8B and C).

The abandoned bends of $\mathrm{FB}$ and $\mathrm{SB}$ show a lack of bedforms throughout much of the bend and instead exhibit a smooth bed texture throughout, which is in contrast to the bedforms observed at PB. Bathymetric maps of FB reveal a triangular-shaped bar at the exit to the abandoned bend, with partial woody vegetation established on the bar top (i.e. bumpy surface texture, Figure $7 \mathrm{C}$ ). It is worthwhile noting that despite the presence of this bar, the abandoned bend of this cutoff site remains hydraulically connected to the main channel even after more than a decade since cutoff initiation. At $\mathrm{SB}$, the exit of the abandoned bend displays a different

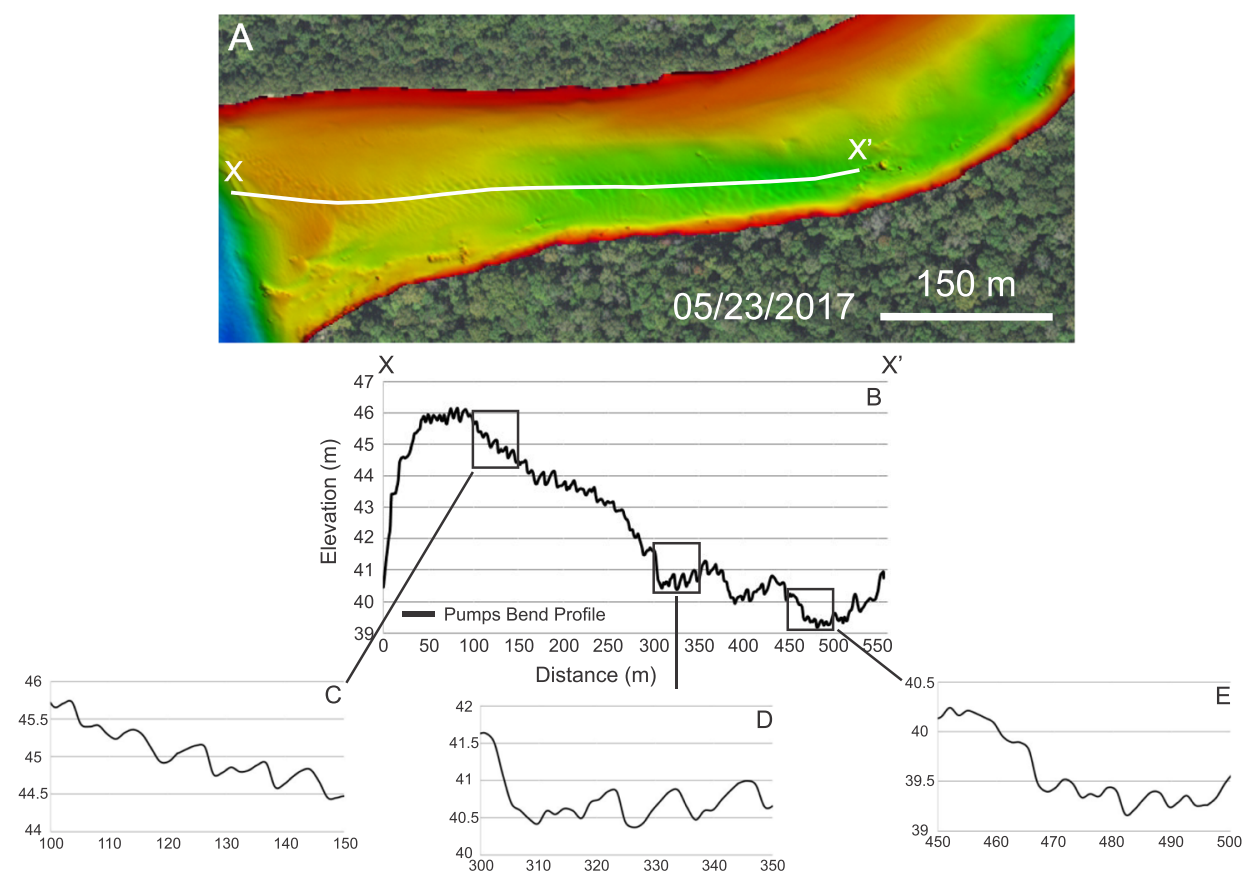

Figure 6. Dune profiles for the exit of the abandoned bend of Pumps Bend 2017. (A) Image of channel morphology at the exit of the abandoned bend. (B) The full dune profile taken, $\sim 550 \mathrm{~m}$, from the exit of the abandoned bend into the downstream portion of the abandoned bend. (C) Dune profile of the 100-150 m section of the full profile. (D) Dune profile of the 300-350 m section of the full profile. (E) Dune profile of the $450-500 \mathrm{~m}$ section of the full profile. [Colour figure can be viewed at wileyonlinelibrary.com] 

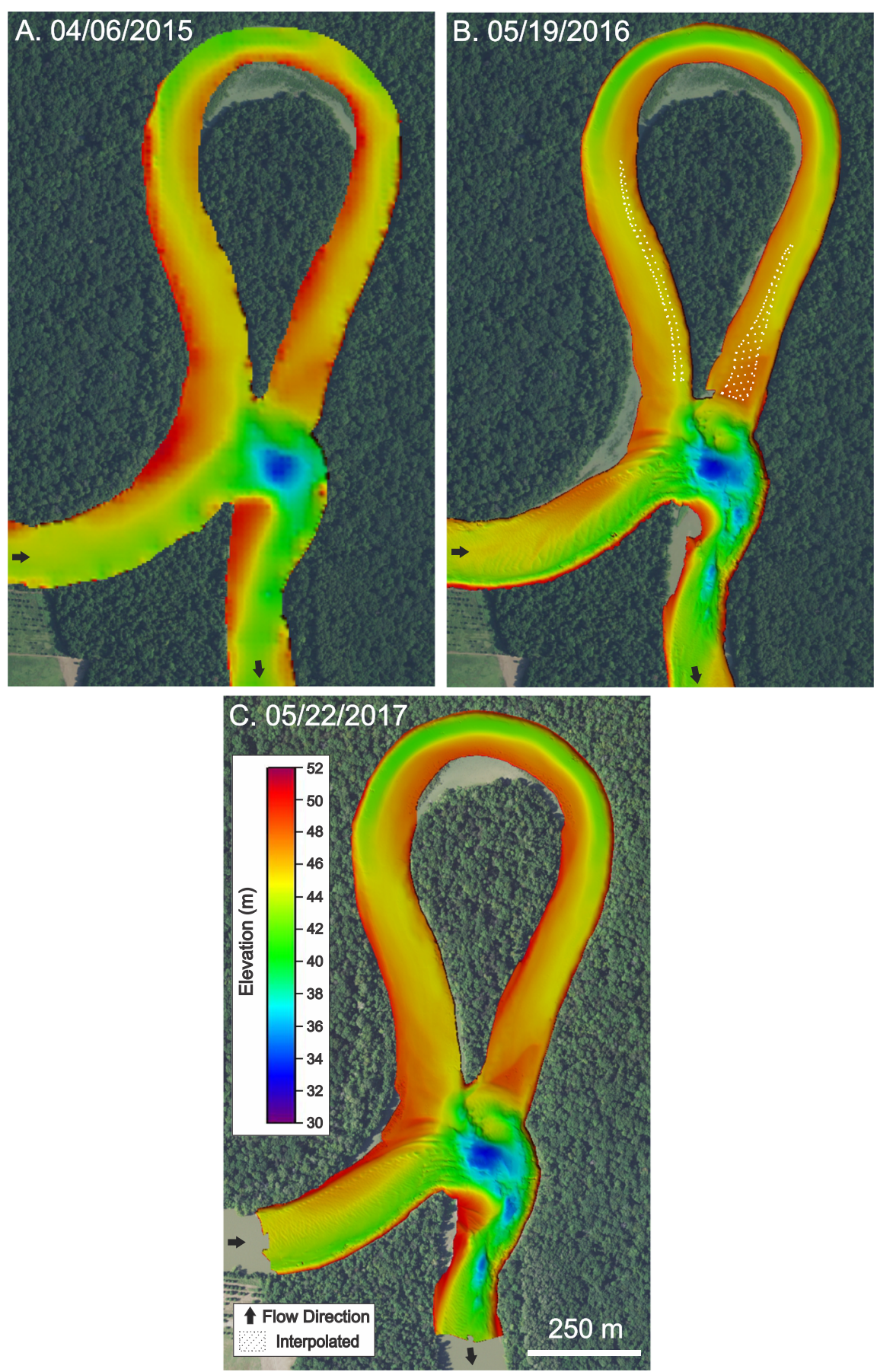

Figure 7. (A) Franklin Bend 2015 channel morphology generated at a $5 \mathrm{~m}$ resolution. (B) Franklin Bend 2016 channel morphology generated at a $1.5 \mathrm{~m}$ resolution. (C) Franklin Bend 2017 channel morphology generated at a $1.5 \mathrm{~m}$ resolution. For all three images, warmer colours represent higher elevations and cooler colours represent lower elevations. Channel morphology located under white dashed polygons indicates areas of relatively larger surface interpolation. [Colour figure can be viewed at wileyonlinelibrary.com]

morphology from $\mathrm{FB}$, with a more gradual increase in elevation, and upstream migrating bedforms that extend $\sim 80 \mathrm{~m}$ into the downstream limb of the abandoned bend.

\subsection{Morphologic changes 2015-2017}

At PB, large areas of erosion and deposition were observed from 2015 to 2017 (Figures 9A-C). Morphologic difference maps calculated between the time intervals allow for quantification of volumetric erosion associated with cutoff widening, channel bed scour, and floodplain/bank erosion, and deposition associated with cutoff bar accretion (Table I). From 2015 to 2016, the volume of erosion associated with widening of the neck cutoff was $\sim 56350 \mathrm{~m}^{3}$ ( 10 $\mathrm{m}$ vertical erosion), increasing in width by $129 \mathrm{~m}$, or $\sim 76 \%$ of the bankfull width. Volumetric scour of the bed was $\sim 163550 \mathrm{~m}^{3}$ (maximum vertical erosion $\sim 12 \mathrm{~m}$ ), and the volume of sediment eroded from the floodplain through bank retreat was $\sim 238310 \mathrm{~m}^{3}$ (Figure 9A). Conversely, the volumetric deposition associated with the cutoff bar was 348 950 $\mathrm{m}^{3}$ (maximum vertical deposition $\sim 12 \mathrm{~m}$; Figure 9A). The 20152016 difference map also shows areas of deposition (up to $5 \mathrm{~m}$ ) and erosion (up to $4 \mathrm{~m}$ ) within the abandoned bend, however these areas were not included in the volumetric rate of change analysis. The net morphologic change was thus calculated to be $\sim 109260 \mathrm{~m}^{3}$ of erosion from 2015 to 2016 .

The morphologic difference map of PB from 2016 to 2017 shows continued widening of the cutoff by $\sim 40 \mathrm{~m}(\sim 24 \%$ of 

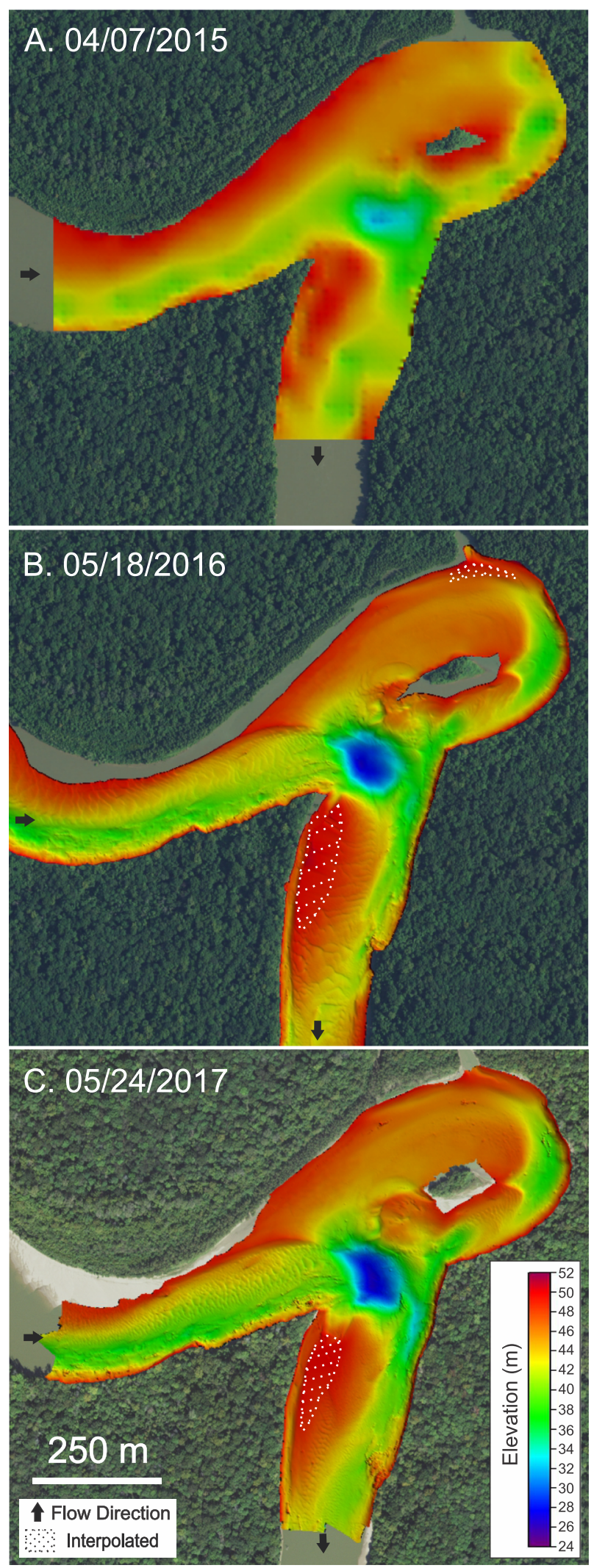

Figure 8. (A) Seven Mile Bend 2015 channel morphology generated at a $5 \mathrm{~m}$ resolution. (B) Seven Mile Bend 2016 channel morphology generated at a $1.5 \mathrm{~m}$ resolution. (C) Seven Mile Bend 2017 channel morphology generated at a $1.5 \mathrm{~m}$ resolution. For all three images, warmer colours represent higher elevations and cooler colours represent lower elevations. Channel morphology located under white dashed polygons indicates areas of relatively larger surface interpolation. [Colour figure can be viewed at wileyonlinelibrary.com]
Table I. Erosion and deposition quantities calculated for the areas outlined in Figure 10. Dimensionless statistics were calculated by dividing erosion and deposition rates by total channel area of the areas where rates were calculated

\begin{tabular}{cccc}
\hline Years & $\begin{array}{c}\text { Deposition } \\
\left(\mathrm{m}^{3}\right)\end{array}$ & $\begin{array}{c}\text { Erosion } \\
\left(\mathrm{m}^{3}\right)\end{array}$ & $\begin{array}{c}\text { Net change (deposition - erosion) } \\
\left(\mathrm{m}^{3}\right)\end{array}$ \\
\hline $\begin{array}{c}2015- \\
2016\end{array}$ & 348950 & 458210 & -109260 \\
$2016-$ & & & -353030 \\
2017 & 288250 & 641280 & -273270 \\
$2015-$ & & & \\
2017 & 472660 & 745930 & \\
\hline
\end{tabular}
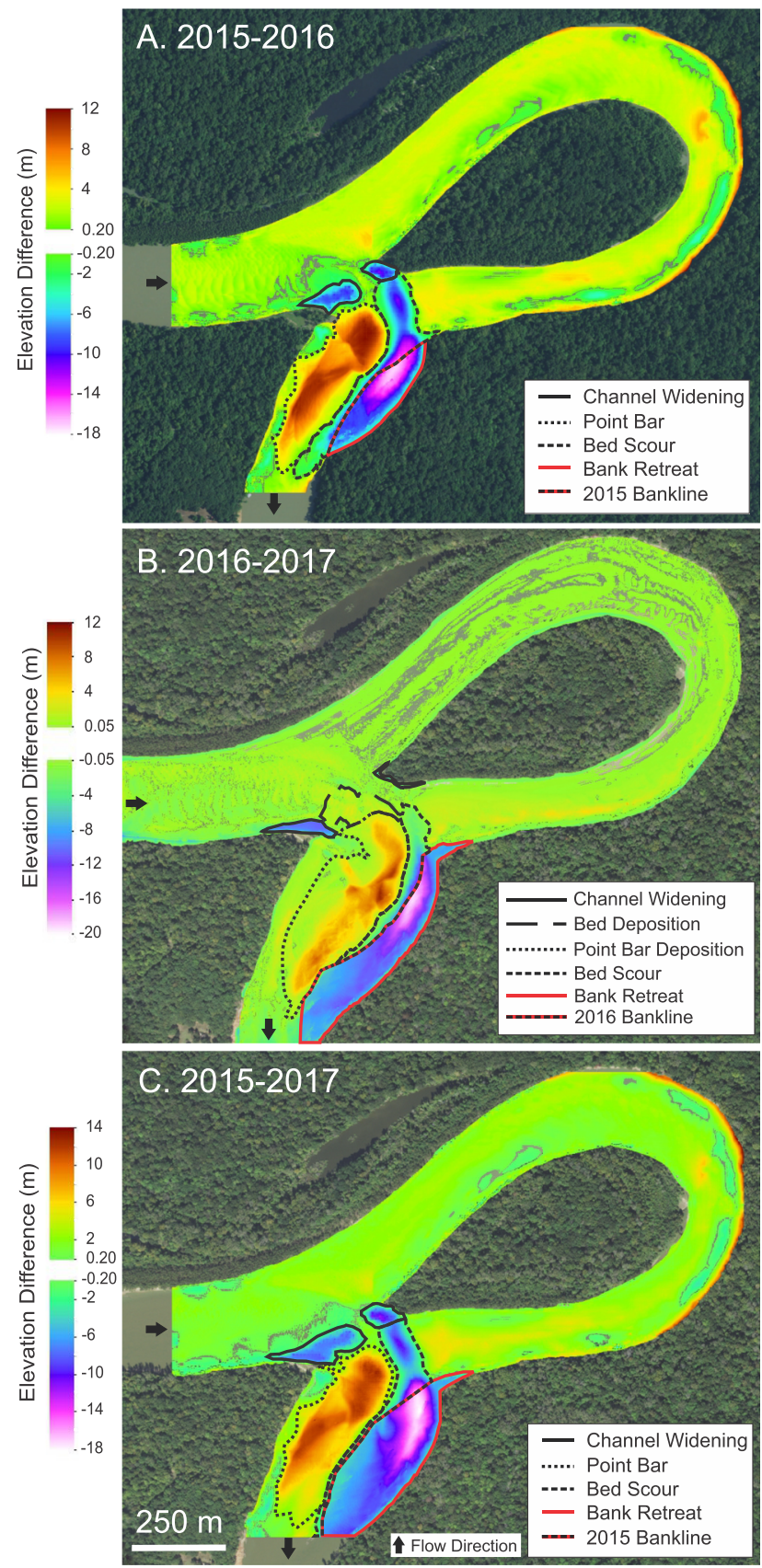

Figure 9. Difference maps of elevation for Pumps Bend neck cutoff surveys between the (A) 2015-2016 surveys, (B) 2016-2017 surveys, and (C) 2015-2017 surveys. The warmer colours indicate increases in elevation and cooler colours indicate decreases in elevation. [Colour figure can be viewed at wileyonlinelibrary.com] 
bankfull width), with a larger area of erosion at the upstream junction corner (Figure 9B). The volumetric erosion due to cutoff widening was calculated to be $\sim 37200 \mathrm{~m}^{3}$, about $34 \%$ less than the 2015-2016 period. Lateral bank retreat during the 2016-2017 period was still rapid, with highest rates of migration $\sim 80 \mathrm{~m}$, and a total volumetric erosion of the floodplain of $\sim 510970 \mathrm{~m}^{3}$ (Figure 9B), which is $\sim 214 \%$ more erosion than the period from 2015 to 2016 . The volume of sediment scoured from the bed during the period 2016-2017 was $70445 \mathrm{~m}^{3}$, or $\sim 57 \%$ less than during 2015-2016. Additionally, the detailed multibeam morphologic maps from 2016 and 2017 allowed for an area of bed aggradation to be identified at the entrance to the point of cutoff, which was estimated to be $\sim 13300 \mathrm{~m}^{3}$ (Figure 9B). Changes to the cutoff bar at PB during 20162017 can be seen as both vertical aggradation $(\sim 4-5 \mathrm{~m})$ on the bar top, and a pronounced lateral expansion of the bar towards the cutbank (Figures 9 and 10). At the head of the cutoff bar, where vertical aggradation is up to $12 \mathrm{~m}$, the bar widened $\sim 95 \mathrm{~m}$, or $\sim 55 \%$ of bankfull width (Figure 10). Farther downstream the bar experienced $\sim 110 \mathrm{~m}$ lateral growth $(\sim 65 \%$ of bankfull width), but only had $\sim 8 \mathrm{~m}$ of aggradation. In total, the cutoff bar was estimated to grow by $\sim 274950 \mathrm{~m}^{3}$, which is $\sim 21 \%$ less than in the $2015-2016$ period. The net morphologic change from 2016 to 2017 was estimated to be 353 $030 \mathrm{~m}^{3}$ of erosion within and downstream of the cutoff, which is over three times more than in the 2015-2016 period. Another remarkable feature observed in the 2016-2017 difference map is the preferential aggradation of $\sim 4 \mathrm{~m}$ within the thalweg of the downstream limb of the abandoned bend, which can be seen extending from the exit of the abandoned bend to the apex (Figure 9B).

The difference map for PB from 2015 to 2017 shows the summary of morphologic changes during the time period. The
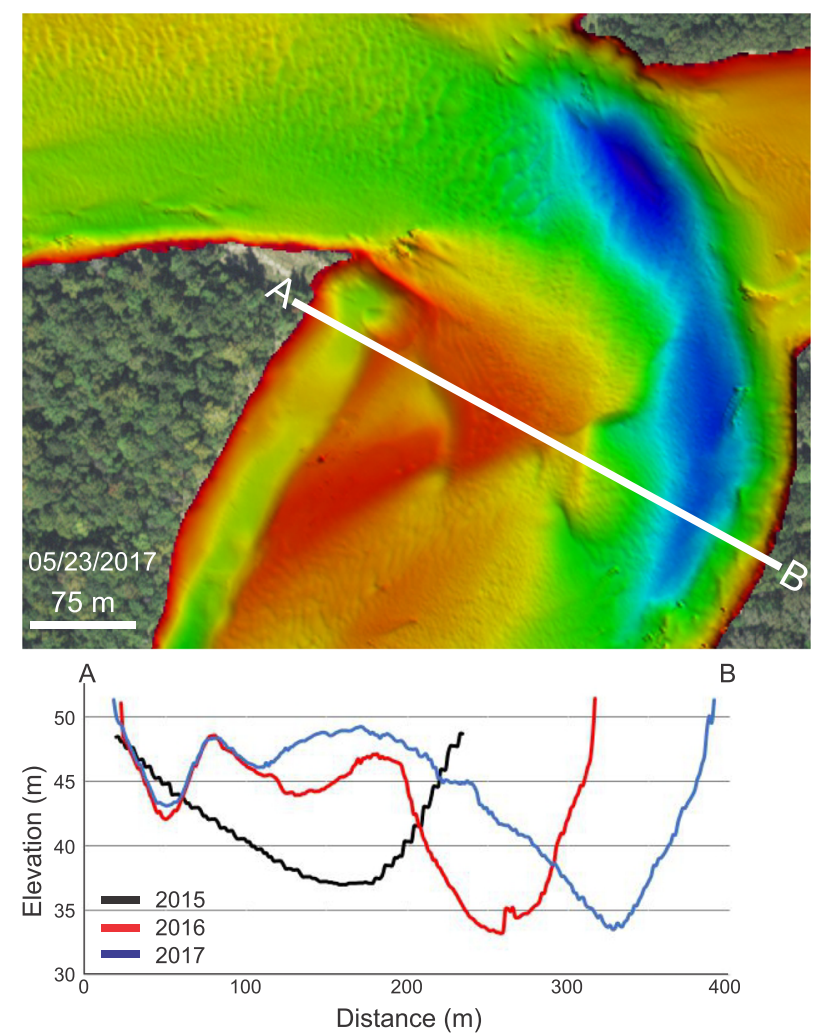

Figure 10. Annual rates of morphologic change from 2015 to 2017 represented along a cross-sectional profile immediately downstream of the neck cutoff on Pumps Bend. Location of cross-section shown on 2017 bathymetric map. [Colour figure can be viewed at wileyonlinelibrary.com] total amount of erosion due to cutoff widening, channel bed scour, and bank retreat was 80 915, 102 880, and 562135 $\mathrm{m}^{3}$, respectively (Figure 9 C). The volume of sediment deposited as the cutoff bar was $\sim 472660 \mathrm{~m}^{3}$, which can be seen in the difference maps as occupying nearly the entire width of the channel prior to cutoff (Figures 9C and 10). The net morphologic change from 2015 to 2017 is $273270 \mathrm{~m}^{3}$ of erosion. Interestingly, the sum of erosion due to bank retreat from the 2015-2016 and 2016-2017 time periods $\left(\sim 749275 \mathrm{~m}^{3}\right)$ is actually $\sim 25 \%$ more than the volume of sediment eroded using the difference between 2015 and 2017. This discrepancy indicates the difference in sediment subsequently deposited as the channel laterally migrates through the floodplain.

Due to the relatively lower rates of geomorphic change observed at both FB and SB during the 3-year time period of this study, difference maps for these two sites were prepared using only the 2016 and 2017 multibeam surveys to investigate the more detailed morphologic changes. The FB 2016-2017 difference map indicates a small amount of erosion throughout much of the upstream limb of the meander bend, likely associated with differences in bedform geometry between the two surveys (Figure 11A). There are, however, four main features worth noting from this difference map. First, along the bank opposite the cutoff there is evidence of relatively minor rates of bank retreat $(\sim 2-5 \mathrm{~m})$, and there appears to be an overall scour-

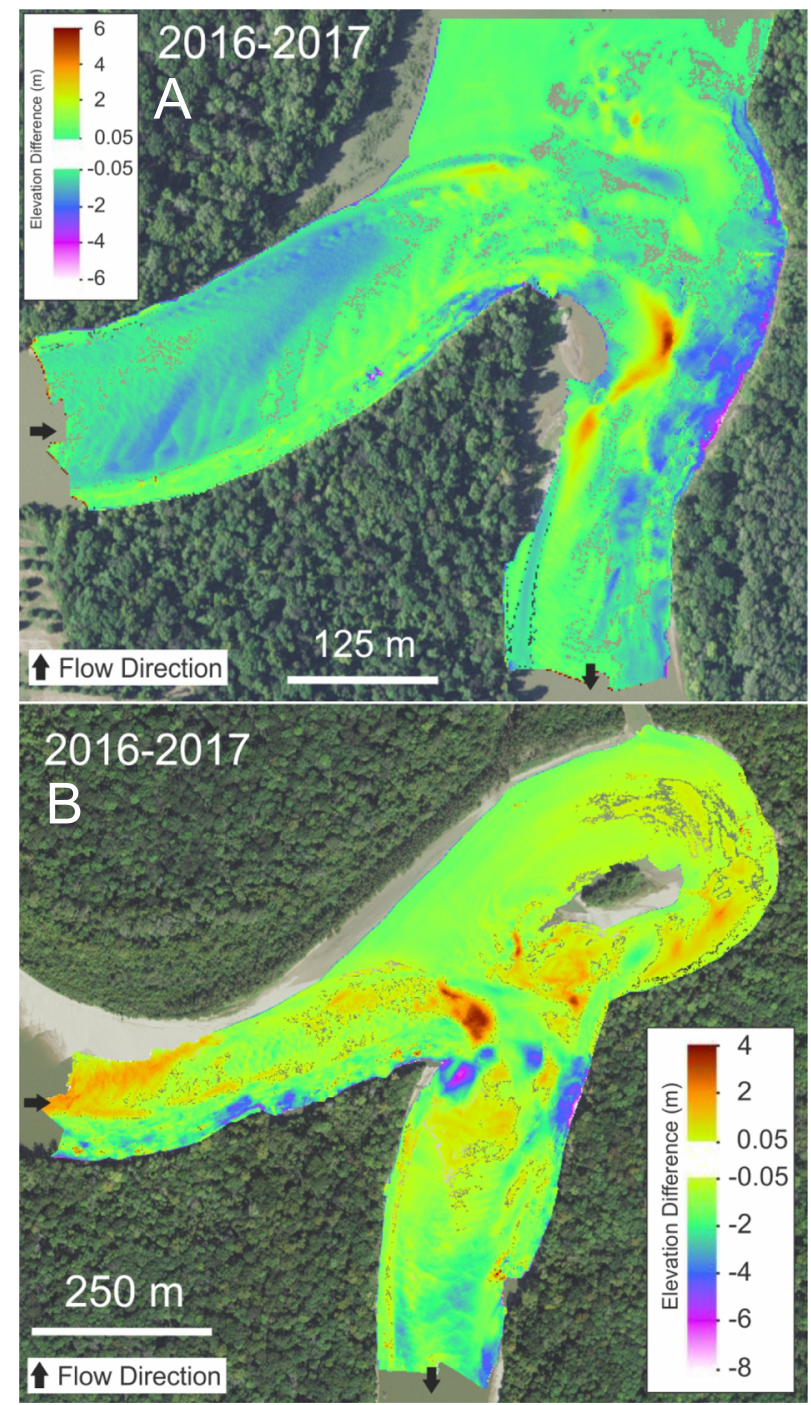

Figure 11. Difference maps of elevation between the 2016-2017 surveys for (A) Franklin Bend and (B) Seven Mile Bend. The warmer colours indicate increases in elevation. The cooler colours indicate decreases in elevation. [Colour figure can be viewed at wileyonlinelibrary.com] 
ing of the channel bed $(\sim 2 \mathrm{~m})$ along the base of the cutbank. Second, the cutoff bar shows continued lateral expansion $(\sim 15 \mathrm{~m}$ wide and $\sim 6 \mathrm{~m}$ vertical) and aggradation on the bar top $\sim 1 \mathrm{~m}$ (Figure 11A). The third area of interest is where the curvilinear ridges (or longitudinal bars) extend from the left bank in the upstream limb of the bend towards the cutoff. In this region, it appears that a new ridge has formed, indicated by the distinct vertical aggradation of $\sim 4 \mathrm{~m}$. Immediately north of this ridge, towards the entrance to the abandoned channel, there is a swale that follows the path of the ridge line. Lastly, between the entrance and exit of the abandoned bend, small pockets of erosion and deposition can be seen (Figure 11A), associated with adjustments to the upstream migrating bars and bedforms identified in the detailed morphologic maps (Figures 7B and C).

The SB 2016-2017 difference map shows noticeable aggradation ( $2 \mathrm{~m}$ ) of the point bar along the left bank of the upstream channel at the farthest upstream extent of the survey area (Figure 11B). Downstream of this area of point bar growth, relatively small areas of erosion (4-6 m) are observed along the thalweg on the right bank. Near the entrance to the cutoff region, a pronounced area of deposition (up to $4 \mathrm{~m}$ ) can be seen that exhibits a slight curvature on its downstream front. Between the entrance and exit to the abandoned bend, a large area of mostly aggradation (up to $4 \mathrm{~m}$ ) is shown, associated with reworking of the bars and bedforms that are locally present (Figure 11B), similar to what was observed for the FB difference map (Figure 10). An obvious band of deposition can be seen within much of the central portion of the abandoned bend, extending from just upstream of the apex to the exit of the abandoned bend, with increasing deposition towards the exit. Interestingly, the entrance to the abandoned bend shows an overall degradation of 0.1-1 m. Downstream of the cutoff, an area of erosion is present along the bank opposite the cutoff that displays erosion up to $8 \mathrm{~m}$ and is roughly $110 \mathrm{~m}$ in length (Figure 11B). The top of the cutoff bar appears to have some aggradation of 1-2 m.

Results from the dimensionless analyses show that FB and SB have similar rates of lateral bank erosion within the first 5 years of cutoff adjustment, with rates of migration decreasing as years since cutoff initiation increase (Figures $12 \mathrm{~A}$ and B). In contrast, the first few years of post-cutoff adjustment at PB show an increase in migration rate, with magnitudes of erosion nearly three times higher than at FB and SB (Figures $12 \mathrm{~A}$ and B). Dimensionless data of cutoff width show moderate variability in rates of change among the three cutoff sites, with all three cutoff widths widening at least 1.4 times the reach-averaged bankfull width (Figure 12C). The cutoff width at SB expanded rapidly to nearly 1.75 times the bankfull width within the first 5 years and appears to have stopped widening. The FB cutoff width also appears to have stopped widening, however the data show that it took nearly a decade for cutoff widening to stabilize. PB cutoff is still relatively early in its evolution, and the data suggest that the cutoff might still experience some widening. Interestingly, despite the differences observed in cutoff widening, all three sites show a roughly logarithmic trend (Figure 12).

\section{Discussion}

The results presented above offer direct insight into the morphologic evolution of neck cutoffs during a 3-year period. However, given that these three cutoff sites have similar planform geometry and are at different stages in the evolution from initial cutoff to oxbow lake, some generalizations can be made regarding the decadal-scale dynamics of neck cutoffs. Prior to cutoff, the bed morphology of the elongate bends would have exhibited asymmetrical cross-sectional profiles, with thalwegs along the upstream and downstream banks of the floodplain
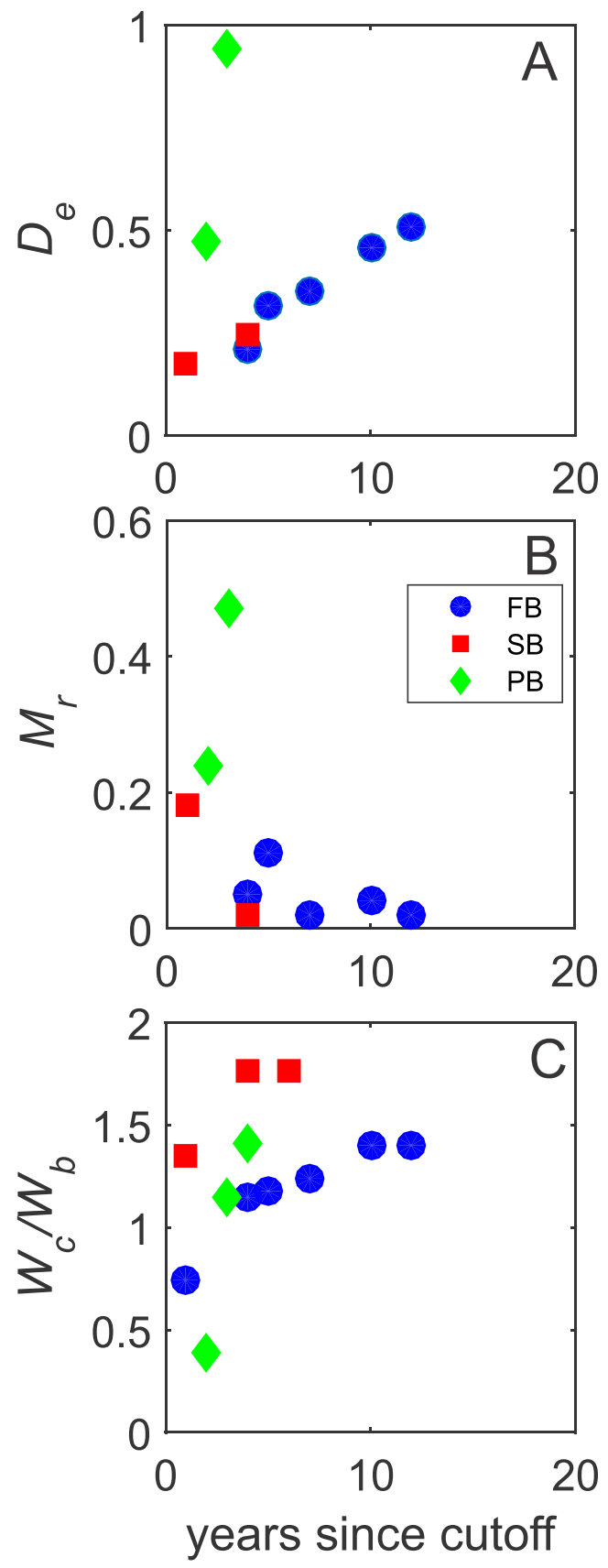

Figure 12. Bathymetric maps showing the difference in deposition within the abandoned bend between Pumps Bend and Franklin Bend. (A) Pumps Bend 2016 abandoned bend morphology. (B) Franklin Bend 2016 abandoned bend morphology. (C) Cross-sectional profiles for the 2016 abandoned loops for Pumps Bend and Franklin Bend (location of cross-sections shown as white lines in A and B). [Colour figure can be viewed at wileyonlinelibrary.com]

neck, and point bars along the banks opposite the floodplain neck. During the initial breach of the floodplain the cutoff is narrow, yet deeply incised due to the increased energy gradient as a result of channel shortening (Figure 5A). During this stage of adjustment roughly $55 \%$ of the flow discharge is conveyed through the cutoff. As a result of the increased energy gradient, as well as acceleration of flow through the narrow cutoff (Figure 3; Konsoer et al., 2016), a deep scour hole develops within the centre of the downstream limb of the elongate bend that is considerably lower in elevation than the surrounding channel bed (Figure 5A).

Following this initial stage of cutoff development, the cutoff widens rapidly to values greater than the reach-averaged bankfull width (Figure 12C), the bank opposite the cutoff in 
the downstream limb experiences substantial erosion and retreat, and the scour hole expands downstream along the newly formed cutbank (Figure 5B). Depending on the planform geometry, the cutoff-widening stage can also be associated with straightening of the upstream limb of the bend (Hooke, 1995). At this stage in the morphologic evolution, the cutoff is effectively capturing the majority of the flow discharge, though the abandoned bend remains hydraulically connected to the main channel (Richards et al., 2018). As flow travelling through the cutoff is redirected nearly $180^{\circ}$ over a short distance, a zone of flow separation and recirculation develops within the downstream limb adjacent to the cutoff (Figure 3; Richards et al., 2018). As a result of this zone of recirculation, as well as rapid bank retreat opposite the cutoff, a large bar develops (Figure $5 \mathrm{~B})$. With this pattern of bar development along the bank adjacent to the cutoff, and scour and erosion along the bank opposite the cutoff, the overall bed morphology and channel curvature are reversed completely from the pre-cutoff morphology.

The detailed multibeam surveys reveal that the cutoff bar is composed of distinctive bar units, where the farthest upstream bar unit is associated with sediment deposition resulting from decreasing bed shear stress as flow travels through the cutoff (like meandering river point bars). These upstream bar units are attached to the floodplain at the cutoff junction and have bar fronts that are perpendicular to the bankline (Figures 5B and $\mathrm{C}$ ). At the downstream tail of the cutoff bar, bedload sediment is transported in the transverse direction from the left bank to the right bank, as evidenced by the orientation of the dune crests (Figures $5 \mathrm{~B}$ and $\mathrm{C}$ ). This pattern of bedload transport is consistent with patterns of three-dimensional flow velocities that show strong inward-directed near-bed flow (Figure 3; Richards et al., 2018). As the bank opposite the bar continues to retreat (often intermittently, associated with large flood events), the bulk discharge of the flow also shifts laterally, resulting in a discrete shift in the area of bar deposition (Figure 5 C). The apparent shift in the location of the unit bars suggests that bank pull is the mechanism responsible for bar growth, rather than bar push (van de Lageweg et al., 2014). As bank retreat slows, the unit bars composing the cutoff bar begin to coalesce, leading to a more uniform point bar morphology (Figures 7C and 8C).

Similarly related to the shifting deposition of the cutoff bar, the curvilinear ridges, or longitudinal bars, observed near the entrance to the abandoned bend appear to be related to episodic bank retreat of the downstream limb (Figures 7B and C). In the early stages of cutoff development, an area of sediment deposition curving across the entrance to the abandoned bend is apparent (Figures 5B and C). Although the amount of aggradation is relatively small, the bed elevation difference is exacerbated by bed degradation leading into the cutoff (Figure 5C). As the channel continues to shift position, new longitudinal bars develop, with consecutive bars increasing in distance from the original location of the entrance to the abandoned bend (Figures 7B and C). Thus, these longitudinal bars and the intervening swales between them resemble scroll bars tracking the migration history of the cutoff.

A noticeable distinction between the neck cutoffs of this study and those of previous investigations is the lack of sediment plugging at the entrance and exit of the abandoned bend, despite more than a decade of time since cutoff in the case of FB (Figure 7). Rates of plugging naturally vary depending on the river planform and amount of sediment load the river transports, yet previous plugging rates have been established at 2 10 years (Gagliano and Howard, 1984), <1-7 years (Hooke, 1995), and $\sim 5$ years (Petersen, 1963) for disparate rivers. The similar time period for plugging indicates that full disconnection should occur within 10 years. One possible explanation for the slow rate of aggradation observed for the neck cutoffs on the White River is related to the deep incision of the channel bed. The increased energy gradient due to the shortening of the stream length across an extremely narrow floodplain neck results in pronounced scour of the bed in the downstream limb, effectively perching the exit of the abandoned bend several metres above the cutoff region (Figures $5 \mathrm{C}$ and $7 \mathrm{C}$ ).

In addition to the above-mentioned perching, the planform geometry of the neck cutoffs in this study results in tight bend flow and well-developed helical motion of the flow through the cutoff (Figure 3; Richards et al., 2018). The strong helical motion of flow observed at these sites produces near-bed flow oriented away from the exit of the abandoned bend, promoting transport of bedload sediment in the downstream direction. In effect, although these sites exhibit high diversion angles between the cutoff and abandoned bend, the tight bend flow through the cutoff and perching of the exit of the abandoned bend lead to conditions that are not conducive for promoting the Bulle effect (Dutta et al., 2017).

Another potential impact of the lack of sediment plugging at the entrance and exit to the abandoned bend is related to the pattern and rate of infilling of the abandoned bend. Previous research on diversion angles of cutoffs has shown that when cutoffs remain unplugged, the abandoned bend shallows and narrows, with lower diversion angles resulting in relatively faster rates of infill (Constantine et al., 2010a; Toonen et al., 2012). Furthermore, previous studies have associated neck cutoffs with higher diversion angles, which are suggested to plug relatively fast, and thus experience slower rates of shallowing and narrowing of the abandoned bend before disconnection (Fisk, 1947; Gagliano and Howard, 1984; Constantine et al., 2010a; Toonen et al., 2012). In contrast, the neck cutoffs of this study have high diversion angles yet lack large sediment plugs that fully disconnect the abandoned bend. As a consequence, the abandoned bends in this study show evidence of pronounced shallowing and narrowing.

This is best exemplified by comparing the bed morphologies of $\mathrm{PB}$ and $\mathrm{FB}$, assuming that morphologic changes through time can be inferred from these two sites that are at different stages of cutoff evolution. A cross-sectional profile through the abandoned bend apices of PB and FB shows that FB has a considerably narrower and shallower profile compared to $\mathrm{PB}$ (Figure 13). Assuming the cross-sectional profile of FB would have been similar to PB shortly after initial cutoff, this finding suggests that these abandoned bends experience significant infilling prior to complete plugging at the entrance and exit. Using the cross-sectional profiles shown in Figure 13C, a conservative rate of infilling is estimated at $70 \mathrm{~cm}_{\text {year }}{ }^{-1}$, which is considerably higher than previous reports of abandoned bend infilling that typically range from 0.1 to $7{\mathrm{~cm} y e a r^{-1}}^{-1}$ (Piégay et al., 2008). Additionally, the morphologic differences observed within the upstream limbs of these two abandoned bends also provide insight into patterns of infill. The upstream limb of PB shows large dunes that appear to have decreased amplitudes and rounded crests, suggesting they are relict bedforms formed during pre-cutoff conditions (Figure 13A). In contrast, the upstream limb at FB displays a smooth texture (Figure $13 \mathrm{~B}$ ) and, given the amount of vertical aggradation inferred from the apex profiles, it is possible that large bedforms might be preserved beneath a relatively thick fill of fine-grained sediment.

The perching of the exit of the abandoned bend above the surrounding channel bed appears to be moderated through time by the development of unit bars between the scour hole and the exit (Figures 7B and C). These unit bars migrate in a direction towards the entrance to the abandoned bend, as 

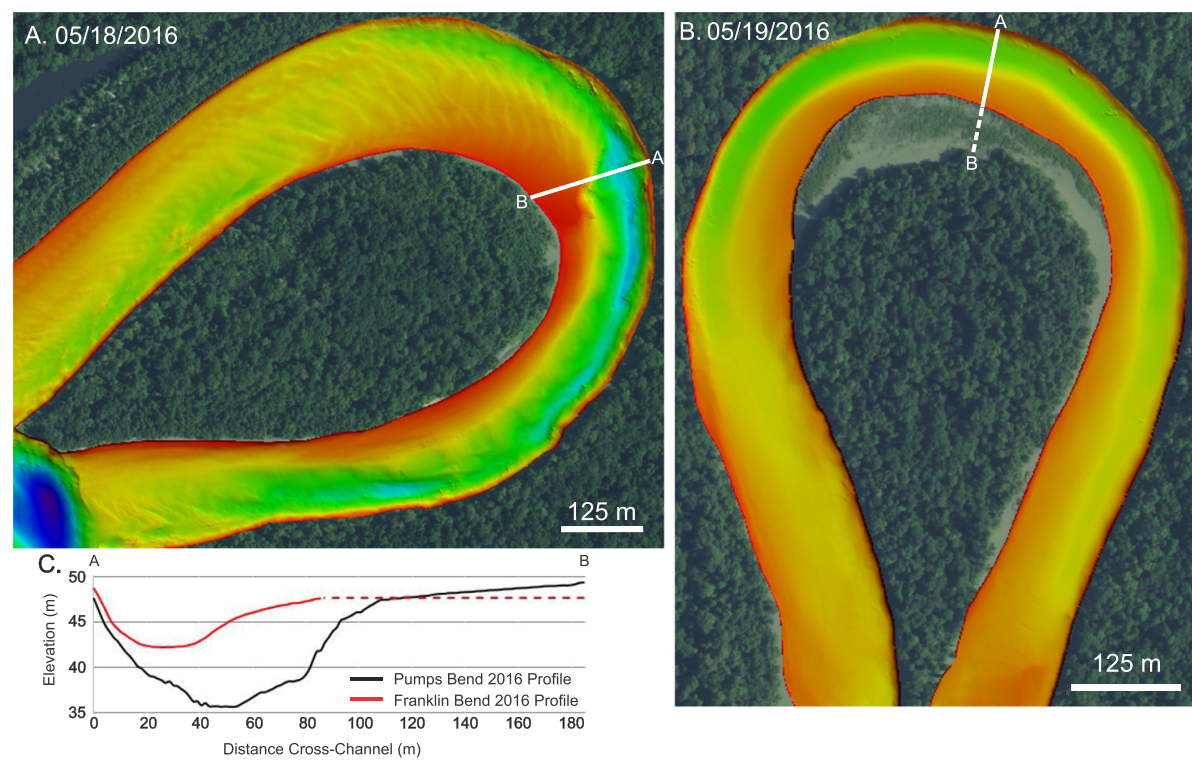

Figure 13. Conceptual model for the initial stages of neck cutoff evolution on highly curving neck cutoffs. (A) Stage 1 of cutoff evolution includes initial floodplain breaching and deep scour hole forming in downstream limb. (B) In Stage 2, the scour hole elongates, relatively rapid rates of erosion along the bank opposite the cutoff and deposition of a cutoff bar adjacent to the cutoff junction corner occur, and the abandoned bend begins to narrow and shallow. (C) During Stage 3, the cutoff bar continues to grow at a rate proportional to bank erosion, a series of longitudinal bars across the entrance of the abandoned bend track with the punctuated events of bank erosion during large flood events, and the abandoned bend continues to shallow and narrow. [Colour figure can be viewed at wileyonlinelibrary.com]

evidenced by the superimposed bedforms and the annual difference maps (Figures 11). The growth of these unit bars is due to the migration of the channel away from the abandoned bend and the presence of a zone of flow recirculation that results in upstream-oriented flow (Figure 3; Richards et al., 2018). The presence of these bars disrupts the abrupt change in elevation (perching) between the scour hole and the exit to the abandoned bend, potentially providing an easier pathway for bedload sediment to plug the exit, as suggested by the plug bar forming in the exit at FB (Figure 7C).

While SB shares many morphologic similarities with $\mathrm{PB}$ and FB, there are some obvious differences. Namely, the location of the cutoff in relation to the original elongate meander planform resulted in a relatively short distance between the cutoff and the apex of the bend (i.e. a short length of channel removed), and thus limited the increase in energy gradient due to cutoff. An outcome of this is that flow traveling from the upstream limb into the cutoff is not as strongly redirected into the downstream limb compared to PB and FB, and a substantial portion of flow travels upstream through the abandoned bend from the exit to the entrance (Richards et al., 2018). This upstream pattern of flow is responsible for the bed morphology observed for the abandoned bend of $\mathrm{SB}$ and the region of upstream migrating bedforms (Figures $8 \mathrm{~B}$ and $\mathrm{C}$ ). A similar pattern of upstream-
A. Stage 1

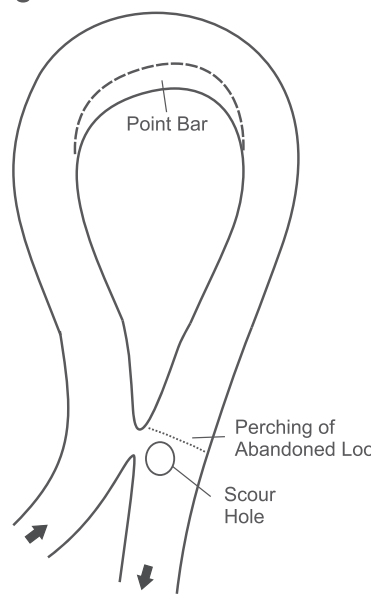

B. Stage 2

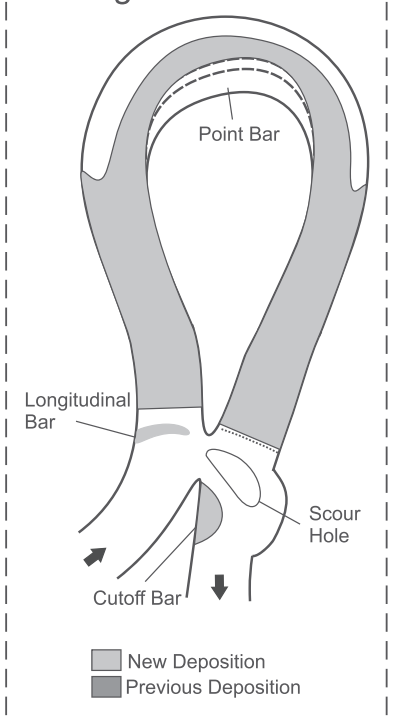

C. Stage 3

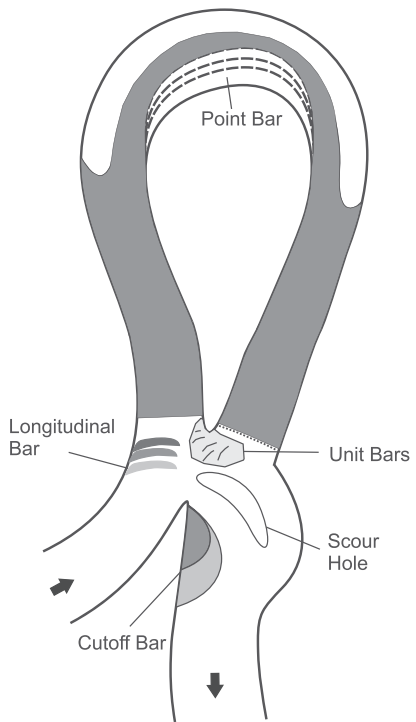

Figure 14. Conceptual model for the initial stages of neck cutoff evolution on highly curving neck cutoffs. A) Stage 1 of cutoff evolution includes initial floodplain breaching and deep scour hole forming in downstream limb. B) In Stage 2, the scour hole elongates, relatively rapid rates of erosion along the bank opposite the cutoff and deposition of a cutoff bar adjacent to the cutoff junction corner occur, and the abandoned bend begins to narrow and shallow. C). During Stage 3, the cutoff bar continues to grow at a rate proportional to bank erosion, a series of longitudinal bars across the entrance of the abandoned bend track with the punctuated events of bank erosion during large flood events, and the abandoned bend continues to shallow and narrow. 
migrating bedforms was seen for the PB 2017 survey, but field measurements have not yet documented upstream-oriented flow through the abandoned bend. One possible explanation is that certain discharge conditions (i.e. large flood events) are more favourable for flow entering the exit of the abandoned bed, but more studies are required to understand those hydrodynamics.

In addition to the differences in bed morphology described above, dimensionless analyses for the three cutoff sites reveal differences in the magnitude and trends of cutoff widening and lateral bank migration (Figure 12). These differences are most likely attributed to the variability in planform geometry, location of cutoff within the bend, distance of channel removed by cutoff, and hydrologic variability following cutoff initiation at each site. However, despite the differences in rates of change, the three neck cutoffs investigated in this study do exhibit an exponential decay in rates of migration (Figure 12), which has also been noted in previous cutoff studies (Hooke, 1995).

The results and discussion provided above are summarized into a conceptual model for the initial stages of morphologic change of highly curved neck cutoffs from initial breaching to stages prior to complete plugging of the abandoned bend (Figure 14). A main difference between the model presented herein and previous conceptual models is the planform geometry and location of the cutoff within the bend. Neck cutoffs have previously been depicted as having a straight channel upstream and downstream of the point of cutoff, or $\Omega$-style (Fisk, 1947; Gagliano and Howard, 1984). The neck cutoffs formed under these straight morphologic conditions do not result in strong curvature of the flow through the cutoff, and thus the range of morphologic features observed in this study, or the hydrodynamics documented in Richards et al. (2018), cannot be explained by the previous long-term conceptual models of neck cutoff evolution. The differences in the conceptual model presented in this study are not meant to provide counter-arguments against previous conceptual models, but rather highlight the importance of planform geometry on the morphodynamic evolution of neck cutoffs and provide insights into neck cutoff evolution that has not yet been provided. Additional detailed investigations should be conducted to test the applicability of this conceptual model for highly curved neck cutoffs on other rivers, such as those shown in Figure 2.

\section{Conclusion}

The morphology of three highly curved neck cutoffs was investigated through detailed annual field measurements of channel bed morphology over a 3-year period. The findings provide new insights into how neck cutoffs on elongate meander bends evolve post-breach but before complete plugging of the abandoned bend, as has already been done for chute cutoffs. Important factors contributing to the morphologic changes observed are summarized below. The location of the cutoff in relation to the elongate bend leads to tight bend flow through the cutoff. Deep channel bed scour immediately downstream of the cutoff, resulting from the increased energy gradient across the cutoff, effectively perches the exit of the abandoned bend several metres above the surrounding channel bed, restricting bedload sediment transport into the exit of the abandoned bend, and limits sediment plugging. High-momentum flow travelling through the cutoff is advected against the bank opposite the cutoff, resulting in rapid rates of bank retreat. Opposite this area of erosion, a cutoff bar develops that is composed of multiple unit bars. As the channel continues its planform evolution through downstream rotation, longitudinal bars deposited across the entrance of the abandoned bend track the migrational history similar to scroll bars.

The morphologic changes documented herein, as well as a recent study examining the hydrodynamics of these same sites (Richards et al., 2018), offer tremendous insight into the morphodynamics of highly curved neck cutoffs that have not been reported on previously. While the three neck cutoffs investigated in this study share many similarities, more work should be done to determine if the conceptual model presented herein is applicable to other neck cutoffs exhibiting similar planform morphology and dissimilar planform morphology. Additionally, numerical modelling of these sites could provide a more thorough understanding of the morphodynamics occurring at these sites, particularly under a range of discharge conditions.

Acknowledgements - We would like to thank Chris Turnipseed and Taylor Rowley for their assistance with field work, and Clint Willson and Jessica LeRoy for helpful discussions throughout this study. We would also like to thank three anonymous reviewers for their helpful comments during the revision process. Funding for this work was provided by a Louisiana State University - Faculty Research Grant and a 2016 West-Russell Research Award from the LSU Department of Geography and Anthropology.

\section{References}

Allen JRL. 1965. A review of the origin and characteristics of recent alluvial sediments. Sedimentology 5(2): 89-91.

Bridge JS, Smith ND, Trent F, Gabel SL, Bernstein P. 1986. Sedimentology and morphology of a low-sinuosity river; Calamus River, Nebraska Sand Hills. Sedimentology 33(6): 851-870.

Brooks G, Medioli B. 2003. Deposits and cutoff ages of Horseshoe and Marion oxbow lakes, Red River, Manitoba. Géographie physique et Quaternaire 57(2-3): 151-158.

Bulle H. 1926. Untersuchungen über die Geschiebeableitung bei der Spaltung von Wasserläufen: Modellversuche aus dem Flussbaulaboratorium der Technischen Hochschule zu Karlsruhe. Düsseldorf: VDI Verlag.

Camporeale C, Perona P, Porporato A, Ridolfi L. 2005. On the long-term behavior of meandering rivers. Water Resources Research 41(12): 1-13. https://doi.org/10.1029/2005WR004109

Camporeale C, Perucca E, Ridolfi L. 2008. Significance of cutoff in meandering river dynamics. Journal of Geophysical Research 113 (F1): 1-11. https://doi.org/10.1029/2006JF000694

Citterio A, Piégay H. 2009. Overbank sedimentation rates in former channel lakes; characterization and control factors. Sedimentology 56(2): 461-482.

Constantine JA, Dunne T. 2008. Meander cutoff and the controls on the production of oxbow lakes. Geology [Boulder] 36(1): 23-26.

Constantine JA, Dunne T, Piégay H, Kondolf GM. 2010a. Controls on the alluviation of oxbow lakes by bed-material load along the Sacramento River, California. Sedimentology 57(2): 389-407.

Constantine JA, McLean SR, Dunne T. 2010b. A mechanism of chute cutoff along large meandering rivers with uniform floodplain topography. Geological Society of America Bulletin 122(5-6): 855-869.

Costigan KH, Gerken JE. 2016. Channel morphology and flow structure of an abandoned channel under varying stages. Water Resources Research 52(7): 5458-5472.

Dieras PL, Constantine JA, Hales TC, Piégay H, Riquier J. 2013. The role of oxbow lakes in the off-channel storage of bed material along the Ain River, France. Geomorphology 188: 110-119.

Dutta S, Garcia MH. 2018. Nonlinear distribution of sediment at river diversions: brief history of the Bulle effect and its implications. Doctoral dissertation, American Society of Civil Engineers.

Dutta S, Wang D, Tassi P, Garcia MH. 2017. Three-dimensional numerical modeling of the Bulle-effect: the non-linear distribution of near-bed sediment at fluvial diversions. Earth Surface Processes and Landforms 42(14): 2322-2337. 
Edwards BL, Keim RF, Johnson EL, Hupp CR, Marre S, King SL. 2015. Geomorphic adjustment to hydrologic modifications along a meandering river: implications for surface flooding on a floodplain. Geomorphology 269: 149-159.

Erskine W, Melville M, Page KJ, Mowbray PD. 1982. Cutoff and oxbow lake. Australian Geographer 15(3): 174-180.

Fares YR. 2000. Changes of bed topography in meandering rivers at a neck cutoff intersection. Journal of Environmental Hydrology $\mathbf{8}$ Paper 13: 1-18.

Fisk HN. 1947. Fine-Grained Alluvial Deposits and their Effects on Mississippi River Activity. Waterways Experiment Station: Vicksburg, MI.

Fuller IC, Large ARG, Milan DJ. 2003. Quantifying channel development and sediment transfer following chute cutoff in a wandering gravel-bed river. Geomorphology 54(3): 307-323.

Gagliano SM, Howard PC. 1984. The neck cutoff oxbow lake cycle along the lower Mississippi River. In River Meandering, Elliott CM (ed). American Society of Civil Engineering: New York; 147-158.

Gay GR, Gay HH, Gay WH, Martinson HA, Meade RH, Moody JA. 1998. Evolution of cutoffs across meander necks in Power River, Montana, USA. Earth Surface Processes and Landforms 23(7): 651-662.

Grenfell M, Aalto R, Nicholas A. 2012. Chute channel dynamics in large, sand-bed meandering rivers. Earth Surface Processes and Landforms 37(3): 315-331.

Grenfell MC, Nicholas A, Aalto R. 2014. Mediative adjustment of river dynamics: the role of chute channels in tropical sand-bed meandering rivers. Sedimentary Geology 301: 93-106.

Han B, Endreny TA. 2014. Detailed river stage mapping and head gradient analysis during meander cutoff in a laboratory river. Water Resources Research 50(2): 1689-1703.

Hooke JM. 1995. River channel adjustment to meander cutoffs on the River Bollin and River Dane, Northwest England. Geomorphology 14(3): 235-253.

Hooke JM. 2004. Cutoffs galore; occurrence and causes of multiple cutoffs on a meandering river. Geomorphology 61(3-4): 225-238.

Ishii Y, Hori K. 2016. Formation and infilling of oxbow lakes in the Ishikari lowland, northern Japan. Quaternary International 397: 136-146.

Johnson RH, Paynter J. 1967. The development of a cutoff on the River Irk at Chadderton, Lancashire. Geography 52(1): 41-49.

Konsoer KM, Richards D, Edwards B. 2016. Planform evolution of neck cutoffs on elongate meander loops, White River, Arkansas, USA. In River Flow 2016, Constantinescu G, Garcia M, Hanes D (eds). CRC Press: Boca Raton, FL; 1730-1735.

Le Coz J, Michalkova M, Hauet A, Comaj M, Dramais G, Holubova K, Piégay H, Paquier A. 2010. Morphodynamics of the exit of a cutoff meander; experimental findings from field and laboratory studies. Earth Surface Processes and Landforms 35(3): 249-261.

Lewis GW, Lewin J. 1983. Alluvial cutoffs in Wales and the Borderlands. Special Publication of the International Association of Sedimentologists 6: 145-154.
Micheli ER, Larsen EW. 2011. River channel cutoff dynamics, Sacramento River, California, USA. River Research and Applications 27 (3): 328-344.

Mosley MP. 1975. Meander cutoffs on the River Bollin, Cheshire in July 1973. Revue de Geomorphologie Dynamique 24: 21-32.

Parsons DR, Jackson PR, Czuba JA, Engel FL, Rhoads BL, Oberg KA, Best JL, Mueller DS, Johnson KK, Riley JD. 2013. Velocity Mapping Toolbox (VMT): a processing and visualization suite for movingvessel ADCP measurements. Earth Surface Processes and Landforms 38(11): 1244-1260.

Petersen MS. 1963. Hydraulic aspects of Arkansas River stabilization. Journal of the Waterways and Harbors Division 89(4): 29-65.

Phillips JD. 2010. The job of the river. Earth Surface Processes and Landforms 35(3): 305-313.

Piégay H, Bornette G, Grante P. 2002. Assessment of silting-up dynamics of eleven cut-off channel plugs on a free-meandering river (Ain River, France). Geomorphology Publication - International Association of Geomorphologists 10: 227-247.

Piégay H, Hupp CR, Citterio A, Dufour S, Moulin B, Walling DE. 2008. Spatial and temporal variability in sedimentation rates associated with cutoff channel infill deposits: Ain River, France. Water Resources Research 44: 1-18, W05420.

Ratzlaff JR. 1981. Development and cutoff of Big Bend meander, Brazos River, Texas. Texas Journal of Science 33(2-4): 121-129.

Richards D, Konsoer K, Turnipseed C, Willson C. 2018. Characterizing three-dimensional flow through neck cutoffs with complex planform geometry. In Fluvial Meanders and Their Sedimentary Products in the Rock Record, Ghinassi M, Colombera L., Mountney NP, Reesink $\mathrm{AJH}$, Bateman M (eds). Special Publication No. 48 of the International Association of Sedimentologists. Chichester: Wiley; 273-295.

Shields FD, Jr, Abt SR. 1989. Sediment deposition in cutoff meander bends and implications for effective management. Regulated Rivers 4(4): 381-396.

Stolum H-H. 1996. River meandering as a self-organization process. Science 5256: 1710-1713.

Stolum H-H. 1998. Planform geometry and dynamics of meandering rivers. Geological Society of America Bulletin 110(11): 1485-1498.

Toonen WHJ, Kleinhans MG, Cohen KM. 2012. Sedimentary architecture of abandoned channel fills. Earth Surface Processes and Landforms 37(4): 459-472.

van de Lageweg WI, van Dijk WM, Baar AW, Rutten J, Kleinhans MG. 2014. Bank pull or bar push: what drives scroll-bar formation in meandering rivers? Geology 42(4): 319-322.

Wren D, Davidson G, Walker W, Galicki S. 2008. The evolution of an oxbow lake in the Mississippi alluvial floodplain. Journal of Soil and Water Conservation 63(3): 129-135.

Zinger JA, Rhoads BL, Best JL, Johnson KK. 2013. Flow structure and channel morphodynamics of meander bend chute cutoffs: a case study of the Wabash River, USA. Journal of Geophysical Research: Earth Surface 118(F4): 2468-2487. 